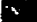

n

\title{
ESTIMATED HEAT CAPACITY, ENTHALPY, THERMAL CONDUCTIVITY, AND DIFFUSIVITY OF SOLID D-T
}

\author{
P. C. Souers \\ R. T. Tzugawa
}

May 4, 1976

Prepared for U.S. Energy Research a Development Administration under contracr No. W-7405-Eng-48

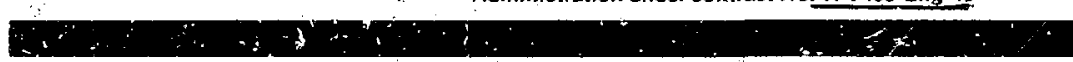

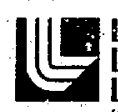

\section{LAWAENCE \\ LNERMOAE LABORATORY}

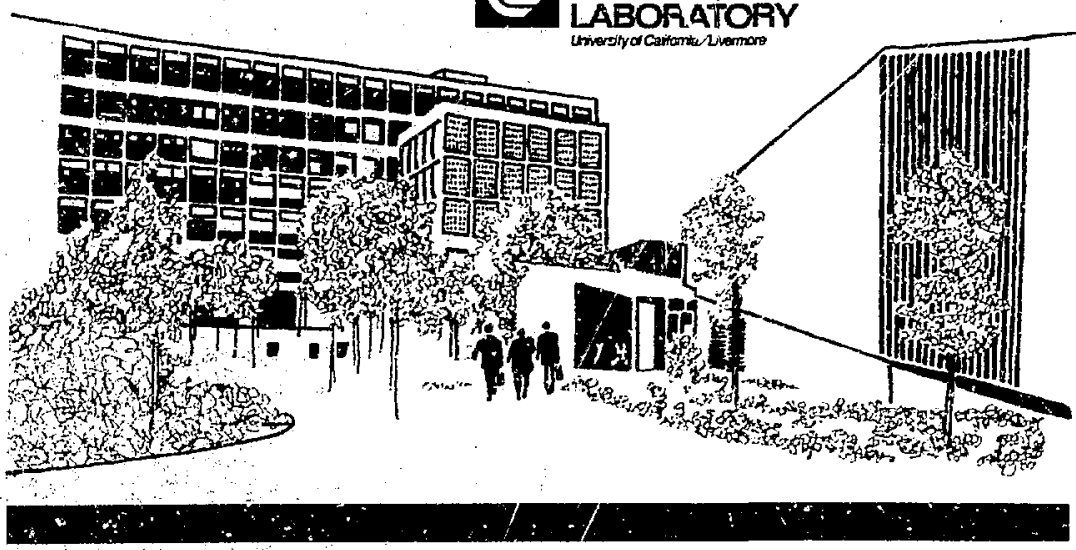

\section{MASTER}




\section{NOTKE}

"Thio report was prepered as an accomal of work sponiored by the Unjted States Gownment. Neither the United States nor the Uniced States Entrey Reseatch \&. Development Admintutration, noc any of theis employect, nor acy of their contrinctors, subcontracton, of their employ ees, mokes any warranty, enpress or Impited, or assumet any iegul Mibtity or responsibility fon the ccurecy, cumpteienes of uneruiness of any information, appatutus. product or process disclont, or tepresents that its use would nof infsinge privately-owned rights."

Printed in the United States of America $\therefore$ Available from

National Technical Information Service

U.S. Department of Commerce

5285 Port Royal Road

Springhteld, VA 22161

Price: Printed Copy S ; Microfiche $\mathbf{5 2 . 2 5}$

Domentic

Pore Ringe

001-025

926-050

$051-075$

$076-100$

101-125

$126-150$

151-175

$176-200$

201-225

226-250

$251-275$

276-300

$301-325$

\section{Price}

S 3.50

4.00

4.50

5.00

5.25 :

5.50

6.00

7.50

7.75

8.00

9.00

9.25

9.75 .

\begin{tabular}{|c|c|}
\hline Pere Rang & $\begin{array}{c}\text { Domestic } \\
\text { Price }\end{array}$ \\
\hline $326-350$ & 10.00 \\
\hline $351-375$ & 10.50 \\
\hline $376-400$ & 10.75 \\
\hline $401-425$ & 11.00 \\
\hline $426-450$ & 11.75 \\
\hline $451-475$ & 12.00 \\
\hline $476-500$ & 12.50 \\
\hline $501-525$ & 12.75 \\
\hline $520-550$ & 13.00 \\
\hline $551-575$ & 13.50 \\
\hline $576-600$ & 13.75 \\
\hline $601-u p$ & $\bullet$ \\
\hline
\end{tabular}

Add $\$ 2.50$ for each additional 100 page Increncti from 601 to I 000 pages: idd $\$ 4,50$ for cach udditional 100 pege incretnent orez 1,600 pages. 


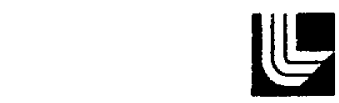

I AWRENCE INERMOAE LABOAATORY

Unversifyol Cattoma Inemme Cationa 94550

I'CRI.- 52068

ESTIMATED HEAT CAPACITY, ENTHALPY, THERMAL CONDUCTIVITY, AHD DIFFUSIVITY OF SOLID D-T

f. C. Sous.r:

R. T. Tsug.juta

May i, 1976

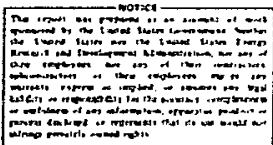




\section{Contents}

symbols. . . . . . . . . . . . . . . . . . . . . . . . . ly Abstract . . . . . . . . . . . . . . . . . . . . . . . 1 Introduct lon . . . . . . . . . . . . . . . . . . . . . . . . i

Expotimencal Data for Cryxtal tatelectleat capaciky . . . . . . . . . . . is Description of Rotacional Encrgy leveln . . . . . . . . . . . . . . Il Rotallonal Heat Capacity . . . . . . . . . . . . . . . . . . . 17 Deseripelon of quadrupolar sublevely fn solid fydrogen . . . . . . . . 21 Daca and Incorprecaclon for Quadrupolar llear Capacicy . . . . . . . . 26 Baste theory of theranal Conductivicy la sioldds . . . . . . . . . . . . 32

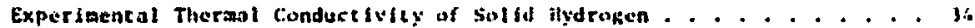
Analysts of theranl Conductivicy . . . . . . . . . . . . . . . 17 Este tonted fiftaces of Radineton Dhange . . . . . . . . . . . . . . . I9

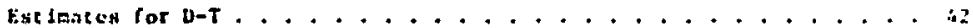

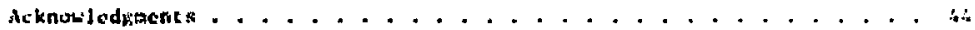

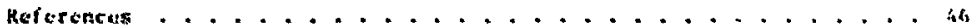

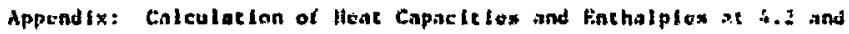

19.7 K......................... . . . . . . 


\section{Symbols}

A11 terms refer to properties measured along the saturated soldd-vapor boundary. The subscript " $S$ " denotes saturacton for total properties only.

A Low-temperature heat capacity constant $\left(\mathrm{J} / \mathrm{mole}-\mathrm{K}^{4}\right.$ )

$B_{L} \quad$ Amplitude constant in expirtcal equations for enchalpy and heat capactey $\left(J /\right.$ mole-K $K^{(1+n)}$ )

$C_{\text {L }}$ Crystal lattice heat capacity (J/mole-K)

$C_{Q}$ Quadrupolar [ $\mathrm{m}_{\mathrm{j}}$-sublevel] heat capacity (J/mole-K)

$C_{Q}^{m} \quad$ Quenched, metastable quadrupolar heat capacity (J/mole-K)

$C_{R}$ Rotational [J-level] heat capacity (J/mole-K)

$C_{R}^{m} \quad$ Quenched, metastable rotarfonal heat capacity (J/mole-K)

$C_{S}$ Total saturated heat capacity (J/mole-K)

$\Delta C_{S} \quad$ Total heat capacity difference between metastable and equilibrium hydrogen ( $J /$ mor̈e-K)

c Kole fraction of $\mathrm{J}-\mathrm{I}$ molecules in a mixture of $\mathrm{J}=0$ and $\mathrm{J}=\mathrm{I}$ (dimenatonlegs)

$c_{J}$ Mole sraction of molecules in the $J^{\text {th }}$ rotational level with any number of total levele (dinensionless)

$D_{S} \quad$ Total saturated thermal diffusivity $\left(\mathrm{m}^{2} / \mathrm{s}\right)$

d Crystal or cryatallite alze (n)

$E_{R} \quad$ Rocactonal Internal [J-level] energy as obtained from statistical wechanics for a perfect gae (J/mole)

$E_{R}^{*} \quad$ Quenched, necastable rotational internal energy (J/mole)

$E_{Q} \quad$ Quadrupolar $\left[m_{J}\right.$-sublevel] incernal energy (J/aole)

$\mathrm{AE}_{\mathrm{J}}$ Rocecional energy gap from the $\mathrm{J}=0$ level to the $\mathrm{J}^{\text {th }}$ level (J/mole)

$b_{C} \quad$ Number of nuclear and nolecular states in $J=0$ rotational energy level (dimeneionlees)

$\mathrm{g}_{1}$ Humber of nuclear and solecular atates in $\mathrm{J}=1$ rotationul energy level (dimenetonless) 
$B_{2} \quad$ Number of nuclear and molecular states in $J=2$ rotactonal energy level (dimensionless)

$H_{L}$ Crystal lattice enthalpy (J/mole)

${ }^{H} Q \quad$ Quadrupolar entha; zy (J/mole)

$H_{Q}^{m} \quad$ Quenched, metastable quadrupolar entialpy (J/mole)

$\mathrm{H}_{\mathrm{S}}$ Total saturated enthalpy ( $\mathrm{J} / \mathrm{mole}$ )

$\Delta H_{S} \quad$ Total enthalpy difference between metastable and equilibrium hydrogen ( $\mathrm{J} / \mathrm{mole})$

I Nuclear spin quantum number (dimensionless)

J Molecular rotational quantum number (dimensioniess)

kd Theral conductivicy due to crystallite boundary scatter Ing (W/m-K)

$K_{r a d}$ Thermal conductivity of heavily Irradlated solic hydrogen (W/m-K)

$\mathrm{K}_{\mathrm{S}} \quad$ Total saturated thermal conductivity ( $\left./ \mathrm{m}-\mathrm{K}\right)$

$K_{u} \quad$ Thermal conductivity due to Umklapp processes ( $\left.W / \mathbb{m}-K\right)$

k Bcltzmann constant ( $1.381 \times 10^{-23} \mathrm{~J} /$ molecule-K)

$m_{J}$ Mulecular rocational sublevel quantum number (dimensionless)

n Temperature exponent in empirical equations for enthalpy and heat chapacy (diciensionless)

Q Molecular rotational par:ition function (dimensionless)

$Q_{Q} \quad Q u a d r u p o l a r$ partition function (dimensionless)

R Gas constant (8.314 j/mole-K)

T Temperature $\left\{K^{\prime}\right.$

4 Speed of sound $(\mathrm{m} / \mathrm{s})$

4 Phonon mean free path determined by Umklapp processes (m)

$\rho_{S}$ Density of solid (mole/m ${ }^{3}$ )

$\theta_{\mathrm{D}} \quad$ Debye ceinperature (K)

$\theta_{\mathrm{D}}^{\mathrm{O}} \quad$ Debye temperature at $0 \mathrm{~K}$ (K)

$\theta_{\mathrm{P}} \quad$ Molecular rotational temperature (K)

${ }_{Q}^{Q} \quad$ Quadrupolar temperature (K) -v- 


\title{
ESTIMATED HEAT CAPACITY, ENTHAI.PY, THERMAL CONDUCTIVITY, AND DIFFUSIVITY OF SOLID D-T
}

\begin{abstract}
Abstraet
We continue our program to estimate the physical properties of che
\end{abstract} thermonuclear fusion fuel, D-T (actually the mixture deuterium-denter lum tritide-tritiuri). We review the ilterature on the heat capacity and thernal conductivfty of solfd hydrogen, hydrogen deuteride, and deuterium. Our discussion of heat capacity and its attendant enthalpy deals with the rrystal lattice, rotational, and quadrupolar mechanisms. For thermal conductiolty, we describe phonon scattering at crystallite boundaries and self-colilstons (Umklapp processes) that reduce the phonon mean fret path. We then dlscuss the effect of rocational energy 1 t. elther reducing crystallite size or causing phonon scattering from quarrupolar subleveis. Thermal diffusivity Is derived from the above propert les plus density. Finally, we est inate all the properties for the solid D-T mixture. Thermal conductivity and diffusivily prove especialiy interesting because they may vary as much as five orders of megnitude as a function of temperature, rotational energy, and radlation damage.

\section{Introduction}

The physical properties of cryogente heavy hydrogen will be of increasingly strong interest in research on hydrogen fusing by laser imploston, ${ }^{1}$ eiectron beam tmplosion, ${ }^{2}$ and magnetic coinfinement. ${ }^{3}$ To aid future cryogentc enginesting, we lwe begun a program to experimentally measure the important propertles of D-T [actually the mixture deuter]umdeuterfum tritide-tritium $\left.\left(D_{2}-D T-T_{2}\right)\right] .{ }^{4}$ We are also reviewing a number of physical properties of hydrogen to extrapolate the values for $D-T$. This program includes collecting and coirelating all the related literature data we can. To date, we have reviewed the phase dlagrani; ${ }^{5}$ liquit density, surface tension, and viscosity; ${ }^{6}$ solid density and refractive index in all phases; ${ }^{7}$ and Infrared vibration-rotation spectra tn the $2-$ to $5-\mu m$ region. ${ }^{8}$ A recent publication summarizes these reviewed properties. ${ }^{9}$

For this report, we shall review the literature data for solli hydrogen $\left(\mathrm{H}_{2}\right)$, hydrogen deuteride (HD), and deuterium. We shal: also estimite 
the heat capacity, enthalpy, thermal conductivity, and thermal difisivity of solid $\mathrm{D}_{2}-\mathrm{DT}-\mathrm{r}_{2}$. For our calculations, we shall f $1 \mathrm{x}$ the D-T rat fw at $1: 1$ to simulate actual fusion fuel. Our calculations shall finvolve five of the six solid hydrogens (hydrogen eritide shall be omfted).

Cryogentc hydrogen studfes center absut the irtple points, where gas, liquid, and solid are in equilfbrfum. The pure component hydrogens have the following criple point cemperatures and pressurrs: 10

\begin{tabular}{|c|c|c|}
\hline Isotope & $\begin{array}{c}\text { Temperucure } \\
(K)\end{array}$ & $\begin{array}{c}\text { Pressure } \\
\text { (Pa) }\end{array}$ \\
\hline $\mathrm{H}_{2}{ }^{\star}$ & 13.80 & 7042 \\
\hline$H D$ & 16.60 & 12400 \\
\hline $\mathrm{D}_{2}$ * & 18.7 & 17130 \\
\hline DT & $19.7 \div$ & $19400^{\circ}$ \\
\hline $\mathrm{T}_{n}{ }^{\star}$ & 20.6 & 21600 \\
\hline
\end{tabular}

All pr-jerties in this report are those along the solld-vapor equilibriua line; 1.e., they are the "saturated" properties. We shall not, therefore. use "S" subscripts to denote saturation except for "total," sumed propertís. The species DT is a pure isotoplc form of hydrogen. However, it wIll chemically equilibrate by the reaction

$$
2 \mathrm{DT} \neq \mathrm{D}_{2}+\mathrm{T}_{2}
$$

at a race that is unknown. The equilibria of this reaction have not been messured at low temperatures but salculations have buen made. 11 These calculations show that "rea]" $1: 1 \mathrm{~L}-\mathrm{T}$ w111 be is solution of the components $\mathrm{D}_{2}-\mathrm{DT}-\mathrm{T}_{2}$ in the proportions: $0.46 / 0.08 / 0.46$ at $4.2 \mathrm{~K}$ and $0.31 / 0.38 / 0.31$ at the triple point of $19.7 \mathrm{~K}$ (est tmated). We shall use these proportiuns in our D-T calculations.

*Actually, for equilibrium- $H_{2}$ and equilibrium $-D_{2}$, with the terms to be defined shorty. Tritium is probably the equilibrium form.

"Est imat ed. 
This heat capacity of the solid hydrogens is a sun of three bechanisms. in descending order of inportance, they are: vibrat fons oi the crystal latefre, rotat ton of the nolecule, and deviatlons of molecular rotation ajused by electric quadrupole forces. The crystal lattice heat capactey is zerw at $0 \mathrm{~b}$, and increases stecply as the teaperature cubed.

Tival enthalpies art qufte small. For fully equillbrated D-T, we ralculate $0.14 \mathrm{~J} / \mathrm{mole}$ at $4.2 \mathrm{~K}$ and $143 \mathrm{~J} / \mathrm{mole}$ at the crlple point. This may be , orpared with the est imated heat of fuston, which is abcut $200 \mathrm{~J} / \mathrm{dole}$. We des not expect the oresence of radiation (frop tratlun) to increase the hear apas ity significia ly. although energy moy Instead be bound up in point

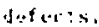

Heat travels through a hydrogen crystal matnly by vitration of the iattice. Thest thernal waves are thought to be lopeded at low temperatures is avstallite buunditifes that cannot bo seen in the optically transparent int. 1s. These insisible crystallites decreasc in size with fncreasing ro.ut tanit enerin portessed by the nolecules.

it lither tamperaturas. the beat cransfer is "scli-. peded" by the

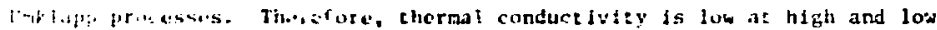
iupperatures and peaks in-between. The bighest peak cortesponds to a thermal - induct lvity between that of room temperatute froti and cungsten. The lowest mi.usured sonductivily (at $0.2 \mathrm{k}$ ) is like that of roop-temgerature alr -- : gond Insulator. At the triple point, the thermal conductivity is like that of ilass or water. Intense radiation may lower the theroal conductfviry as much is five decades at lwa temperafures but should have little effect near the triple point. The time needer for radlation cffects to take place is completely unknown.

Heat caparity and enthalpy may be estimated for D-T without too many qualms. However, the ther.oal corductivity, whish ranges over four to five decades depending on the particular parameters, leaves many uncertainties. These uncertainties are passed on alrectly to the theraal diffusibty.

A knowledge of the thermal conductivity will be essential for any fuston dPplicat ion involving frozen DT. This propezty varjes many decades between insulator and conductor. A knowledge of it s eccentrinities wtll be essential to enginee.ing the removal of any large amount of radioactive decay s.eat. Several questions are ố considerable sclentific interest: Do crystallites really exist in solid hydrogen? What kind of radiatica danage cakes place? 
Are the rotational or quadrupolar energies avallable for heat conduction?

In summary, we present estimated values of heat capacity, enthalpy, thermal conductivity, and thermal diffusivity for solid $D-T$. These values, In the absence of actual data, will allow materials engineering of upcoming cryogenic laser targets. We feel that a measurement of the thermal conductivir: of solid D-T is of high priority (because we expect it to vary as nuch as five decades as a function of temperature, rotational energy, and radiation damage).

\section{Experimental Data for Crystal Lattice Heat Capacity}

Considerable solid heat capacity data has been taken. ${ }^{12-30}$ Host of it is saturated of at constant pressure, which we shall take to be the same. This Is because $\mathrm{H}_{2}$ vapor pressure at $25 \mathrm{~K}$, our highest temperature of interest, is only $0.3 \mathrm{MPa}$ ( $3 \mathrm{~atm}$ ); and this is not enough to compress the crystal lattice. We shall not consider pressure studies that yield heat capacity at constant volume.

A quick listing of solid hydrogen heat capacity data Includes: $\mathrm{H}_{2}{ }^{12-23}$; $\mathrm{HD}^{13,24,25}$; and $\mathrm{D}_{2} \cdot 13,16,19,20,22,26-30$ Mixtures of $\mathrm{H}_{2}$ and $\mathrm{D}_{2}$ are also reported. 19-22 Much of the data is reported in the recent National Bureau of Standards (NBS) cryogenic hydrogen survey. ${ }^{31}$ Figure 1 shows some heat capacity data for solid $\mathrm{H}_{2} \cdot{ }^{31}$ The rotational effects* (to be described later) are quite obvious at low temperatures but die out as the temperature is raised. We shall first consider only data that contain no rotational effects. Such data are a function of the crystal lattice heat capacity, $C_{L}$.

The crystal lattice heat capacity arises from lattice vibrations, which form a continuous spectrum of energies up to some cutoff point. The cutoff energy is directly proportional to the Debye temperature, $\theta_{D}$, of the lattice. The heat capacity associated with lattice vibrational energy levels rises steeply at low temperatures, then saturates and becomes constant at high temperatures - a characteristic of systems with an infinite number of energy levels. The saturation occurs at actual temperatures comparable to $\theta_{D^{*}}$ The Debye function used in this theory does not admit of a simple analytical

*The numbers in Fig. 1 are the mole fractions of $\mathrm{H}_{2}$ molecules in the first exclted rotational state $(J=1)$. The remainder are in the ground state $(J=0)$. Data "without rotational effects" actually have a 0 to $2 \% \mathrm{~J}=1$ admixture. 
The heat capacity of the solid hydrogens is a sum of three mechanisms. In descending order of Importance, they are: vibrations of the crystal lattice, rotation of the molecule, and deviations of molecular rotation raused by electric guadrupole forces. The crystal lattice heat capacity is $z$ tro at $0 \mathrm{~K}$ and increases steeply as the temperature cubed.

Total enthalpies are quite small. For fully equilibrated D-T, we calculate $0.14 \mathrm{~J} /$ mole at $4.2 \mathrm{~K}$ and $143 \mathrm{~J} /$ mole at the triple point. This may be compared with the estimated heat of fusion, which is about $200 \mathrm{~J} / \mathrm{mole}$. We do not expect the presence of radiation (from tritium) to fncrease the heat capacity significantly, although energy may instead be bound up in point defects.

Heac travels through a hydrogen crystal mainiy by vibration of the lattice. These thermal waves are thought to be impeded at low temperatures by crystallite boundarles that cannot be seen in the optically transparent crystals. These invisible crystalites decrease in size with increasing rotational energy possessed by the molecules.

At higher temperatures, the heat transfer is "self-impeded" by the Umkiapp processes. Therefore, thermal conductivity is low at high and low temperatures and peaks in-between. The highest peak corresponds to a thermal conductivity between that of room temperature fron and tungsten. The lowest measured conductivity (at $0.2 \mathrm{~K}$ ) is like that of room-tewperature air -- a good insulator. At the triple point, the thermal conductivity is like that of glass or water. Intense radiation may lower the thermal conductivity as much as five decades at low temperatures but should have little effect near the triple point. The time needed for radiation effects to take place is completely unknown.

Heat capacity and enthalpy may be estimated for D-T without too many qualms. However, the thermal conductivity, which ranges over fout to five decades depending on the particular parameters, leaves many uncercainties. These uncertaintles are passed on directly to the thermal diffusivity.

A knowledge of the thermal conductivity will be essential for any fusion application involving frozen DT. This property varies many decades between insulator and conductor. A knowledge of its eccentricities will be essential to engineering the removal of any large amount of radloactive decay heat. Several questions are of considerable scientiflc Interest: Do crystallites really exist in solid hydrogen? What kind of radiation damage takes place? 
Are the rotational or quadrupolar energles available for heat conduction?

In summary, we present estimated values of heat capacily, enthalpy, thermal conductivity, and thermal diffusivity for solid $D-T$. These values, in the absence of actual data, will allow materlals engineerfing of upcoming cryogenic laser targets. We feel that a measurement of the thermal conductivity of solid D-T is of high priority (because we expect it to vary as much as five decades as a function of temperature, rotational energy, and radiation damage).

\section{Experimental Data for Crystal Lattice Heat Capacity}

Considerable solid heat capacity data has been taken. ${ }^{12-30}$ Most of it f.s saturated or at constant pressure, which we shall take to be the same. This Is because $\mathrm{H}_{2}$ vapor pressure at $25 \mathrm{~K}$, our highest temperature of interest, is only $0.3 \mathrm{MPa}(3 \mathrm{~atm})$; and this is not enough to compress the crystal lattfce. We shall not consider pressure studies that yield heat capacity at constant volume.

A quick listing of solid hydrogen heat capactity data includes: $\mathrm{H}_{2}{ }^{12-23}$; $\mathrm{HD}^{13,24,25}$; and $\mathrm{D}_{2} \cdot 13,16,19,20,22,26-30$ Mixtures of $\mathrm{H}_{2}$ and $\mathrm{D}_{2}$ are also reported. 19-22 Much of the data is reported $1 \mathrm{n}$ the recent National Bureau of Standards (NBS) cryogentc hydrogen survey. ${ }^{31}$ Figure 1 shows some heat capacity data for solid $\mathrm{H}_{2} \cdot{ }^{31}$ The rotational effects* (to be described later) are quite obvious at low temperatures but die out as the temperacure is raised. We shall first consider only data that contain no rotational effects. Such data are a function of the crystal lattice heat capacity, $C_{L}$.

The crystal lattice heat capactty arises from lattice vibrations, which form a continuous spectrum of energies up to some cutoff point. The cutoff energy is directly proportional to the Debye temperature, $\theta_{D}$, of the lattice. The heat capacity associated wtth lattice vibrational energy levels rises steeply at low temperatures, then saturates and becomes constant at high temperatures - a characteristic of systems with an Infinite number of energy levels. The saturation occurs at actual temperatures comparable to $\theta_{D^{\prime}}$ The Debye function uaed in this theory does not admit of a sfmple analytical

*The numbers in FIg. 1 are the mole fractions of $\mathrm{H}_{2}$ molecules in the first excited rotational state $(\mathrm{J}=1)$. The remainder are in the ground state $(\mathrm{J}=0)$. Data "without rotational effects" actually have a 0 to $2 \% \mathrm{~J}=1$ admixture. 


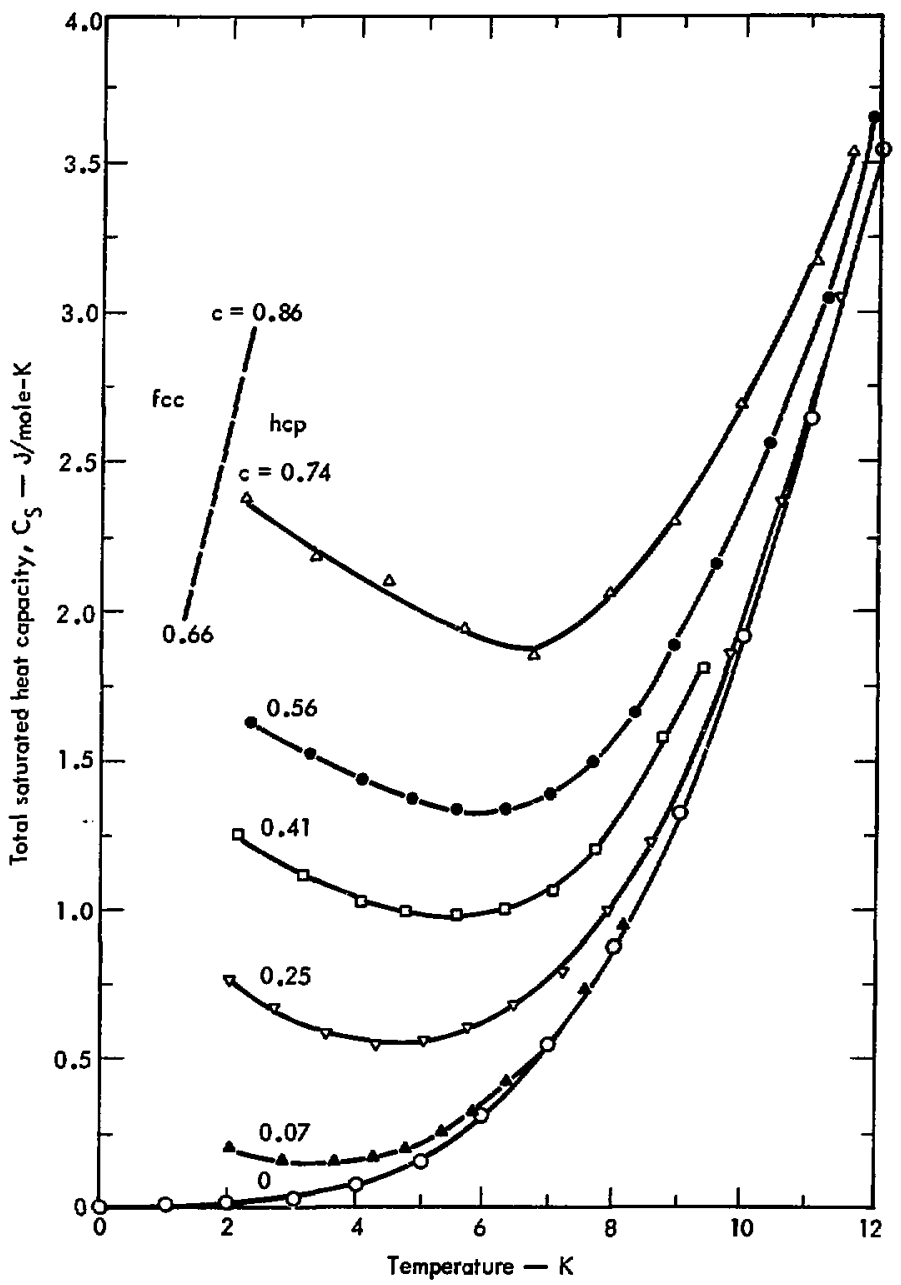

Fig. 1. Total saturated heat capacity, $\mathrm{C}_{\mathrm{S}}$, of solld $\mathrm{H}_{2}$, Hatched line represents hcp $\rightarrow$ fc transformation; $c$ represents mole fraction $J=1$ state. 
expression, but for temperatures less than $0.1 \theta_{D}$, the heat capacity reduces to the form

$$
C_{L}=A_{L} T^{3}
$$

where $C_{L}$ is the lattice heat capacity along the saturation line of solid-vapor equilibrium and $A_{L}$ is the low-temperature heat-capacity constant. ${ }^{32}$

From eq. (1), we expect $A_{L}$ to be a constant. In practice, this is not quite true and many slightly different values of $A_{L}$ have appeared in the 1fterature. We, therefore, summarize all crystal lattice heat capacity data in Fig. 2, which shows $A_{L}$ plotted as a function of temperature for $H_{2}$, 13-17 $\mathrm{HD}, 13,24,25$ and $\mathrm{D}_{2}, 13,16,26,28$ It can be seen that $A_{L}$ is not truly constant but rises to a peak at about $12 \mathrm{~K} . *$ we note (with details to follow) that $\theta_{D}$ for solid hydrogen is $100-120 \mathrm{~K}$, so that the $0.1 \theta_{D}$ mark is exceeded near the triple points. For temperatures above $0.1 \theta_{D}$, the Debye function grows less rapldly than $\mathrm{T}^{3}$. This produces the downward turn seen at high temperatures in Fig. 2. The upward behavior of $A_{L}$ in Fig. 2 is caused by a decrease In $\theta_{D}$ with increasing temperature. This is shown in Fig. 3 for Debye

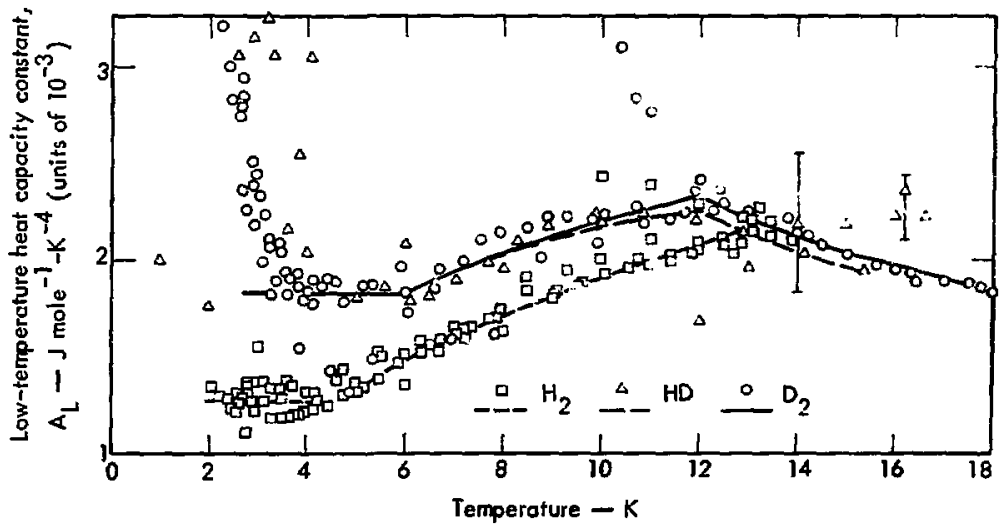

$F_{-\infty}$ 2. Low-temperature heat capacity constant, $A_{L}$, of $J=0$ solfd hydragen.

*There is considerable scatter in the high-temperature HD data, but the downward polnts of Ref. 24 are undoubtedly the best. The $J=1$ molecules in low concentration cause a rise at $2 \mathrm{~K}$. 


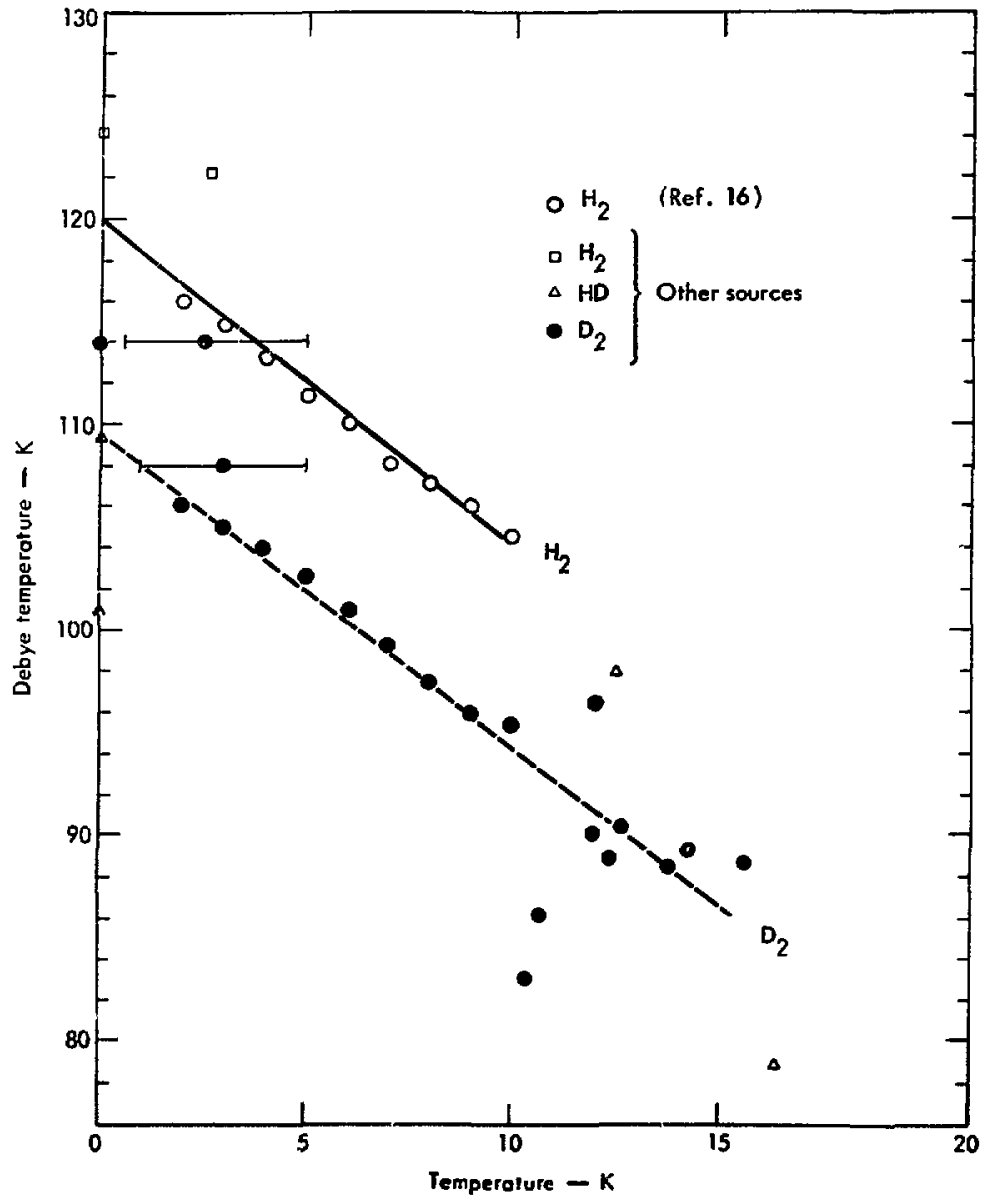

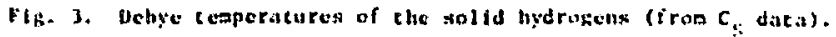


temperatures (from the literature) as derfived from the heat capacity data. $13,16,21-26,28,30$ Frow further theory, we expect $A_{L}$ to be proportional to $\theta_{D}^{-3}$. If $\theta_{D}$ decreaties, $A_{L}$ becomes larger. Hence, two effects conbine to render $A_{L}$ not really a constant. 32,33

We now return to summarize the $A_{2}$ data of Fig. 2 . We have chosen to break the curves into three temperature intervals, so that a function capable of easy integration may be used. The heat capacity is this function mulitplied by $T^{3}$, or just

$$
c_{1}=B_{L} T^{n}
$$

The enthalpy associated with the lattice is

$$
H_{L}=\frac{\mathrm{B}_{L} T^{n+1}}{n+1}-\text { (constant). }
$$

Table 1 contains the numerical constants for calculating the heat capactey and enthalpy for $H_{2}, H D$, and $D_{2}$ from $0 \mathrm{~K}$ to the triple points. The constants $B_{L}$ and $n$ in the enthalpy equations have been adjusted for all lower-temperature Intervals.

We have used Eqs. (2) and (3) with Table 1 and calculated values of $c_{1}$ and $h_{2}$ at varlous temperatures for the hydrogens. Table 2 shows these. Because the $\mathrm{HD}$ and $\mathrm{D}_{2}$ data are almost the same, we use $\mathrm{D}_{2}$ data to estimate DT and $T_{2}$ values. The criple polnt enthalpies increase from $D_{2}$ to $T_{2}$ even with the use of the same data, however, because triple point temperatures Increase from $D_{2}$ to $T_{2}$. We note also the extremely small $\mathrm{B}_{L}$ and $C_{L}$ values at liquid helium temperature.

As approximate equations for the hydrogens in the range $0 \mathrm{~K}$ to the triple points, we compress Table 1 to the forms

$$
\begin{aligned}
& c_{\mathrm{L}} \simeq \begin{cases}1.7 \times 10^{-3} \mathrm{~T}^{3}, & \mathrm{H}_{2} \\
2.0 \times 10^{-3} \mathrm{~T}^{3}, & \text { all others, } \\
\mathrm{J} / \text { mole }-\mathrm{K},\end{cases} \\
& \mathrm{H}_{\mathrm{L}} \approx \begin{cases}4.2 \times 10^{-4} \mathrm{~T}^{4}, & \mathrm{H}_{2} \\
5.0 \times 10^{-4} \mathrm{~T}^{4}, & \text { all others, } \\
\mathrm{J} / \text { mole } .\end{cases}
\end{aligned}
$$


Table 1. Leat capacity and enthalpy of the hydrogen crystal lattice. Using $D_{2}$ values for DT, we estimate at the triple point of $19.7 \mathrm{~K}, \mathrm{C}_{\mathrm{L}}=13.5 \mathrm{~J} / \mathrm{mole}-\mathrm{K}, \mathrm{H}_{\mathrm{L}}=74 \mathrm{~J} / \mathrm{mole}$. For $\mathrm{T}_{2}$, we estivate at the triple point of $20.6 \mathrm{~K}, \mathrm{C}_{\mathrm{L}}=15.1 \mathrm{~J} /$ mole- $\mathrm{K}, \mathrm{v}_{\mathrm{i}}=87 \mathrm{~J} / \mathrm{mole}$. A11 enthalpy equations have been adjusted for the lower temperature segments preceding them.

\begin{tabular}{|c|c|c|c|c|c|}
\hline \multirow[t]{2}{*}{ Isotop } & \multicolumn{5}{|c|}{$\begin{array}{l}\text { Saturated crystal lattice heat capacity, } \mathrm{C}_{L} \\
\text { (J/mole-K) }\end{array}$} \\
\hline & $\begin{aligned} & \mathrm{H}_{2}(0-4.5 \mathrm{~K}) \\
& \mathrm{HD}, \mathrm{R}_{2}(0-6 \mathrm{~K}) \\
&\end{aligned}$ & $\mathrm{HD}, \mathrm{D}_{2}\left(\begin{array}{l}(4,5-12 \mathrm{~K}) \\
(6-12 \mathrm{~K})\end{array}\right.$ & $\begin{array}{l}12 k \text { to the } \\
\text { triple point }\end{array}$ & $\begin{array}{l}\text { Values at } \\
4.2 \mathrm{~K}\end{array}$ & Values at triple points \\
\hline \multirow{3}{*}{$\begin{array}{c}\mathrm{H}_{2} \\
\mathrm{HD} \\
\mathrm{D}_{2}\end{array}$} & $\begin{array}{l}1.27 \times 10^{-3} \mathrm{~T}^{3} \\
1.82 \times 10^{-3} \mathrm{~T}^{3}\end{array}$ & $\begin{array}{l}6 \times 10^{-4} \mathrm{~T}^{3.50} \\
1.1 \times 10^{-3} \mathrm{~T}^{3.29}\end{array}$ & $\begin{array}{l}6 \times 10^{-4} \mathrm{~T}^{3.50} \\
1.05 \times 10^{-2} \mathrm{~T}^{2.38}\end{array}$ & $\begin{array}{l}0.09 \\
0.13\end{array}$ & $\begin{array}{l}5.9 \text { at } 13.80 \mathrm{~K}(0 \mathrm{~J}=1) \\
6.1 \text { at } 13.96 \mathrm{~K}(\mathrm{n}-) \\
8.4 \text { at } 16.60 \mathrm{~K}\end{array}$ \\
\hline & $1.82 \times 10^{-3} \mathrm{~T}^{3}$ & $10^{-3} \mathrm{~T}^{3.34}$ & $8.8 \times 10^{-3} T^{2.46}$ & 0.13 & 11.9 at $18.7 \mathrm{~K}(0 \mathrm{~J}=1 ; \mathrm{n})$ \\
\hline & \multicolumn{5}{|c|}{$\begin{array}{l}\text { Saturated crystal lottice enthalpy, ht } \\
\text { ( } \mathrm{J} / \text { mole) }\end{array}$} \\
\hline $\begin{array}{r}\mathrm{H}_{2} \\
\mathrm{HD}\end{array}$ & $\begin{array}{l}3.18 \times 10^{-4} \mathrm{~T}^{4} \\
4.55 \times 10^{-4} \mathrm{~T}^{4}\end{array}$ & $\begin{array}{l}1.33 \times 10^{-4} T^{4.5} \\
2.56 \times 10^{-4} T^{4.29}\end{array}$ & $\begin{array}{l}1.33 \times 10^{-4} \mathrm{~T}^{4.5} \\
3.11 \times 10^{-3} \mathrm{~T}^{3.38}-2.9\end{array}$ & $\begin{array}{l}0.10 \\
0.14\end{array}$ & $\begin{array}{l}17.9 \text { at } 13.80 \mathrm{~K}(0 \mathrm{~J}=1) \\
18.9 \text { at } 13.96 \mathrm{~K}(\mathrm{n}-) \\
39 \text { at } 16.60 \mathrm{~K}\end{array}$ \\
\hline $\mathrm{D}_{2}$ & $4.55 \times 10^{-4} \mathrm{~T}^{4}$ & $2.30 \times 10^{-4} T^{4.34}$ & $2.54 \times 10^{-3} \mathrm{~T}^{3.46}-2.7$ & 0.14 & 61 at $18.7 \mathrm{k}(0 \mathrm{~J}=1 ; \mathrm{n}-)$ \\
\hline
\end{tabular}


Table 2. Smoothed values of crystal lattice heat capacity and enthalpy. From Eqs. (2) and (3) and Table 1.

\begin{tabular}{|c|c|c|c|c|c|c|}
\hline \multirow[t]{2}{*}{$\begin{array}{l}\text { Temperature } \\
\text { (K) }\end{array}$} & \multicolumn{3}{|c|}{$\begin{array}{c}\text { Lattice heat capacity, } c_{L} \\
(\mathrm{~J} / \text { mole-K) }\end{array}$} & \multicolumn{3}{|c|}{$\begin{array}{l}\text { Lattice tnthalpy, } \mathrm{H}_{\mathrm{L}} \\
\text { (J/mole) }\end{array}$} \\
\hline & $\mathrm{H}_{2}$ & $H D$ & $\mathrm{D}_{2}$ & $\mathrm{H}_{2}$ & $\mathrm{HD}$ & $\mathrm{D}_{2}$ \\
\hline 2 & 0.01 & 0.01 & 0.01 & 0.005 & 0.007 & 0.007 \\
\hline 4 & 0.08 & 0.12 & 0.12 & 0.08 & 0.12 & 0.12 \\
\hline 6 & 0.32 & 0.39 & 0.39 & 0.42 & 0.59 & 0.59 \\
\hline 8 & 0.87 & 1.0 & 1.0 & 1.5 & 1.9 & 1.9 \\
\hline 10 & 1.9 & 2.1 & 2.2 & 4.2 & 5.0 & 5.0 \\
\hline 12 & 3.6 & 3.9 & 4.0 & 9.6 & 10.9 & 11.1 \\
\hline 13.80 & 5.9 & 5.4 & 5.6 & 17.9 & 19.3 & 19.6 \\
\hline 13.96 & 6.1 & 5.6 & 5.8 & 18.9 & 20.1 & 20.5 \\
\hline 14 & - & 5.6 & 5.8 & - & 20.4 & 20.8 \\
\hline 16 & - & 7.7 & 8.1 & - & 33.6 & 34.5 \\
\hline 16.60 & - & 8.4 & 8.8 & - & 38.5 & 39.6 \\
\hline 18 & - & - & 10.8 & - & - & 53.3 \\
\hline 18.7 & - & - & 11.9 & - & - & 61.3 \\
\hline 19.7 & - & - & $(13.5)^{\mathrm{a}}$ & - & - & $(73.9)^{\mathrm{a}}$ \\
\hline 20 & - & - & $(14.0)^{a}$ & - & - & $(77.9)^{a}$ \\
\hline 20.6 & - & - & $(15,1)^{a}$ & - & - & $(86.9)^{\mathrm{a}}$ \\
\hline
\end{tabular}

${ }^{3}$ Extrapolated for DT and $T_{2}$. For lower temperatures, use $D_{2}$ values as estimates (In paretheses)? 
We may also simplify the Debye temperature data of FIg. 3, using mostly the data of Ref. 16. We employ the empirical formula

$$
\theta_{D}=\theta_{D}^{\circ}-1.6 \mathrm{~T}
$$

where $\theta_{\mathrm{D}}^{\circ}$ is the Debye temperature at $0 \mathrm{~K}$ and has values of 120 , 110, and $110 \mathrm{~K}$ for $\mathrm{H}_{2}, \mathrm{HD}$, and $\mathrm{D}_{2}$. The $\mathrm{HD}$ is extremely scattered, but we feel the $0 \mathrm{~K}$ value of $110 \mathrm{~K}$ to be the more accurate value at this time. ${ }^{24}$ Both the $\mathrm{H}_{2}$ and $\mathrm{D}_{2}$ data yield 1.6 for the second constant in Eq. (6), and the same value $f_{j} ;$ assumed for $\mathrm{HD}$. We assume $\theta_{\mathrm{D}}^{0}$ estimates of $110 \mathrm{~K}$ for both $\mathrm{DT}$ and $\mathrm{T}_{2}$, along with the same temperature coefflctent of 1.6. Eçs. (2) and (6) are the besi fits to the data, and they will not perfectly relate to each other through the Debye function.

Finally, the heat capacities of $\mathrm{H}_{2}-\mathrm{D}_{2}$ mixtures have been measured from $0.6-5 \mathrm{~K}^{22}$ and from $8 \mathrm{~K}$ to the triple point mixtures. 19,20 Within error, the lattice heat capacitles of the mixtures may be equated to the linear combinations of the pure component heat capacities.

\section{Description of Rotational Energy Levels}

The diatomic hydrogen molecules possess rotational energy levels, described by the quantum number $\mathrm{J}$. The moleculas are spread over many energy levels at room temperature but are almost completely in the $J=0$ and 1 states below $25 \mathrm{~K}$. When the temperature is rapidly lowered, specles such as HD or DT deexclte rapldly hecause of their lack of molecular symmetry. They are always in the equilibrium (e) state. The equilibrium of states at room teinperature is called normal $(n)$.

Because of their molecular symmetry, $\mathrm{H}_{2}, \mathrm{D}_{2}$, and $\mathrm{T}_{2}$ do not totally deexcite when the temperature is quickly lowered. All of the even-nuabered rotational levels drop to the $J=0$ ground state; all of the odd-numbered levels fall to the $J=1$ first excited state. However, the $J=1$ to $J=0$ excitation takes weeks unless catalyzed. For example, $T_{2}$ w11l equilibrate In tens of minutes because of the catalyzing effects of 1 ts beta particje. $5,34-36$ Because the $\mathrm{J}=1$ to $\mathrm{J}=0$ deexcitation is almost completely forbidden for $H_{2}, D_{2}$, and $T_{2}$, we have the possibllity of holding large quantities of metastable rotational energy upon dropping the temperature. We are able, 
for example, to have roor temperature $\mathrm{H}_{2}$ and $\mathrm{D}_{2}$ stable for days at cryogenic temperatures.

Thus, $\mathrm{H}_{2}, \mathrm{D}_{2}$, and $\mathrm{T}_{2}$, each separate into "types" of hydrogen. The type with even-numbered J-levels we call "symetric", although it is mor a conmonly called "para" for $\mathrm{H}_{2}$ and $\mathrm{T}_{2}$ and "ortho" for $\mathrm{D}_{2}$. The type with odd-numbered $\mathrm{J}$-leveis we call "antisymetric", although it is commonly called "ortho" for $\mathrm{H}_{2}$ and $\mathrm{T}_{2}$ and "para" for $\mathrm{D}_{2}$. Actual hydrogen is a mixture of symetric and antisymetric forms with the same definition of equilibrium and normal.

The possession of metastable rotatlonal energy has little effect on most physical properties of the hydrogens. This is especially true in the gas and liquid phases. Rotational effects are of extreme importance, however, In the description of the thermal properties of the solfd. We shall carefully delineate the two mechanisus caused by population of the molecular rotational energy levels.

The term "rotational," as applied to heat capacity, can be confusing, because there are two distinct mechanisms. The first is heat absorbed by transitions to higher rotational states of the dlatomic molecule. These rotational states have a quantum number label, $\mathrm{J}, \boldsymbol{w}$ th zero being the ground state. There are an infinite number of rotational levels, although only the lowest two are of major Importance below $25 \mathrm{~K}$. The term "rotational," with the subscript "R," will be applied to propertles associated with these J-levels.

A second set of rotationally related properties occurs only in the solid state. An internal force, due largely to electric quadrupolar interactions, creates a magnetic field that splits each rotational J-level into $2 J+1$ sublevels labeled with the quantum number, m $\mathrm{J}$. We shall call the thermal propertien assoclated with these sublevels "quadrupolar," with the subscript "Q."

In this section, we shall calculate the rotational level populations; 1.e., the number of molecules in the various J-levels. The splittings of the rotational levels are given by the rotational temperature, $\theta_{R}$, which may be considered a constant for each species. It declines with molecular weight and has the following values: $\mathrm{H}_{2}=87.5 \mathrm{~K}$, HD=65.7 K, $\mathrm{D}_{2}=43.8 \mathrm{~K}, \mathrm{DT}=36.7 \mathrm{~K}$ (our eatinate), and $T_{2}=29.2 \mathrm{k} .{ }^{37^{2}}$

We have already mentioned the metastable aspects of the rotational energy for the species: $\mathrm{H}_{2}, \mathrm{D}_{2}$, aud $\mathrm{T}_{2}$. We now add a second property pecullar to these three specieg, but not present in HD and DT. In the $H_{2}$, 
$\mathrm{D}_{2}$, and $\mathrm{T}_{2}$ molecules, the rotational and nuclear magnetic fields lock together. This means that the distribution of rotational states partly depends on the number of nuclear magnetic atates.

Let us consider HD and DT first, since their case is simpler. The rotational partition function, $Q_{R}, 1 s^{38,39}$

$$
Q_{R}(H D \text { and } D T)=\sum_{J=0}^{\infty}(2 J+1) \exp \left[-\frac{J(J+1) \theta_{R}}{T}\right] \text {. }
$$

This basic function contains, for HD and DT, only rotational conponents - no nuclear effects enter. The energy jump to the Jth rotational level from the ground state is

$$
\Delta \mathrm{E}_{\mathrm{J}}=\mathrm{J}(\mathrm{J}+1) \mathrm{R \theta}_{\mathrm{R}}
$$

The fractional population of the Jth level, $c_{J}$, Is

$$
c_{J}=\frac{(2 J+1) \exp \left|-\frac{J(J+L) \theta_{R}}{T}\right|}{Q_{R}} \text {. }
$$

For $\mathrm{H}_{2}, \mathrm{D}_{2}$, and $\mathrm{T}_{2}$, the nuclear and rotational magnetic moments are locked together. The rotational partition function will actually be a product of rotational and nuclear terms. The nuclear epin quantum nutmiers, $I$, for $H, D$, and $T$ in thefr ground states are $1 / 2,1$, and $1 / 2$, respectively. For $\mathrm{H}_{2}$ and $\mathrm{T}_{2}$, the two $1 / 2$ values combine to yield a total molecular nuclear spin of 0 or 1 . Each of these states fossesses $(2 I+1)$ substates, or 1 and 3 , respectively. The $I$ - 0 nuclear state combines with the odd-numbered .I-levels and the I = 1 nuclear states combine with the even-numbered J-levels. The partition function for $\mathrm{H}_{2}$ and $\mathrm{T}_{2}$ is

$$
\begin{aligned}
Q_{R}\left(H_{2} \text { and } T_{2}\right) & =\sum_{\substack{J=0 \\
\text { Even }}}^{\infty}(2 J+1) \exp \left[-\frac{J(J+1) \theta_{R}}{T}\right] \\
& +3 \cdot \sum_{\substack{J d d \\
\text { Odd }}}^{\infty}(2 J+1) \exp \left[-\frac{J(J+1) \theta_{R}}{T}\right] .
\end{aligned}
$$

We see that the partition function oplits into two parts, corresponding to the two "typeg" of hydrogen. The even-J terp is the oymecric (para) Ind 
the odd-J antisymmetric (ortho). We shali use the old symmetric-antisymmetric terminology from Dennison's 1927 heat capacity paper, 40 because the more widespread ortho-para terms are reversed in definition for $\mathrm{D}_{2}$, thus causing confusion.

At high temperatures (room temperature is close), the rocational populations of $\mathrm{H}_{2}$ and $\mathrm{T}_{2}$ spread over many levels. We find $25 \%$ in the symmetric srate and $75 \%$ in the antisymmetrlc, corresponding to the 1 and 3 weightings of the terms in Eq. (10). The term "ortho" refers to that type in greater nuantity at room temperature.

For $\mathrm{D}_{2}$, the nuclear spins of $I=1$ combine to $y$ leld the molecular sums of 0,1 , and 2 , with $(2 I+1)$ sublevels of 1,3 , and 5 . The $\operatorname{six} 0$ and 2 substates combine with the even-J rotational levels and the three span 1 substates combine with the odd-J rotational levels. The partition function for $\mathrm{D}_{2}$ is

$$
\begin{aligned}
Q_{R}\left(D_{2}\right)= & 6 \cdot \sum_{\substack{J=0 \\
\text { Even }}}^{\infty}(2 J+1) \exp \left[-\frac{J(J+1) \theta_{R}}{T}\right] \\
& +3 \cdot \sum_{\substack{J=0 \\
\text { Odd }}}^{\infty}(2 J+1) \exp \left[-\frac{J(J+1) \theta_{R}}{T}\right] .
\end{aligned}
$$

At high temperatures, we have $6 / 9$ or $66-2 / 3 \%$ symmetric $D_{2}$ and $33-1 / 3 \%$ antisymerric $D_{2}$, corresponding to the 6 and 3 weightings in $E q$. (11). Since the symmetric form is in greater quantity at room temperature, the even-J $D_{2}$ Is called "ortho" - exactly the opposite from $\mathrm{H}_{2}$ and $\mathrm{T}_{2}$.

We no' wish to calculate the equilibrium rotational populations for the saturated hydrogens from 0 to $25 \mathrm{~K}$. In this temperature range, the first Three ter.15 ( $J=0,1$, and 2) are sufficient to calculate all quantitles. As we shall see, two terms are generally sufficient. The partition function representing the first three rotational levels is

$$
\mathrm{Q}_{R}=g_{0}+3 g_{1} \exp \left(-\frac{2 \theta}{T}\right)+5 g_{2} \exp \left(-\frac{6 \theta}{T}\right)
$$

whe' $=g_{0}, g_{1}$, and $g_{2}$ are the number of nuclear spin states assocfated with the $\mathrm{J}=0,1$, and 2 rotational levels. These are calculated from Eqs. (7), (10), and (11). T'yey are summarized in Table 3. Using Eq. (9), we calculate the three-level rotational level populations. Figure 4 shows the results. 
Table 3. Rotational temperature and number of states associated with first three rotational energy levels.

\begin{tabular}{|c|c|c|c|c|c|}
\hline \multirow[t]{2}{*}{ lsotupe } & \multirow{2}{*}{$\begin{array}{c}\text { Rotat Lona } 1 \\
\text { temper at ure, } \\
37 \\
\text { (K) }\end{array}$} & \multicolumn{3}{|c|}{ Number of states } & \multirow{2}{*}{$\begin{array}{l}\text { Coeffictent for } \\
\text { metastable } \\
\text { energy, } \mathrm{E}_{\mathrm{R}} \\
\left(\frac{{ }_{\mathrm{B}}}{\mathrm{B}_{0}+{ }^{3} \mathrm{~B}_{1}}\right)\end{array}$} \\
\hline & & $\varepsilon_{0}$ & $\mathbf{B}_{1}$ & $\mathbf{g}_{2}$ & \\
\hline $\mathrm{H}_{2}$ & 87.5 & 1 & 3 & 1 & 1.8 \\
\hline $\mathrm{HD}$ & 65.7 & 1 & 1 & $\mathbf{1}$ & 1.5 \\
\hline $\mathrm{D}_{2}$ & 43.8 & 6 & 3 & 6 & 1.2 \\
\hline DT & $(36.7)^{a}$ & 1 & 1 & 1 & 1.5 \\
\hline $\mathrm{T}_{2}$ & 29.2 & 1 & 3 & 1 & 1.8 \\
\hline
\end{tabular}

iEstimated value.

$\mathrm{T}_{2}$ is the most easily excited, as we world expect, because it has tire lowest rotational temperature.

The experimental data that led to the formation of the bydrogen rotational theory was taken in 1929. 40 In 1965, the equilibriur symetric-antisymmetric ratios were measured for $\mathrm{H}_{2}$ gas at 24 to $248 \mathrm{~K}, \mathrm{D}_{2}$ gas at 22 to $132 \mathrm{~K}$, and $T_{2}$ gas at 21 to $77 \mathrm{~K} .{ }^{36}$ The measured and calculated symetric hydrogen concentrations differed by on $1 \mathrm{y} 1.6$ and 0.6 mole\% for $\mathrm{H}_{2}$ and $\mathrm{D}_{2}$, but by 6.0 mole\% for $T_{2}$. It was thought that the tritium beta particle was the cause. 


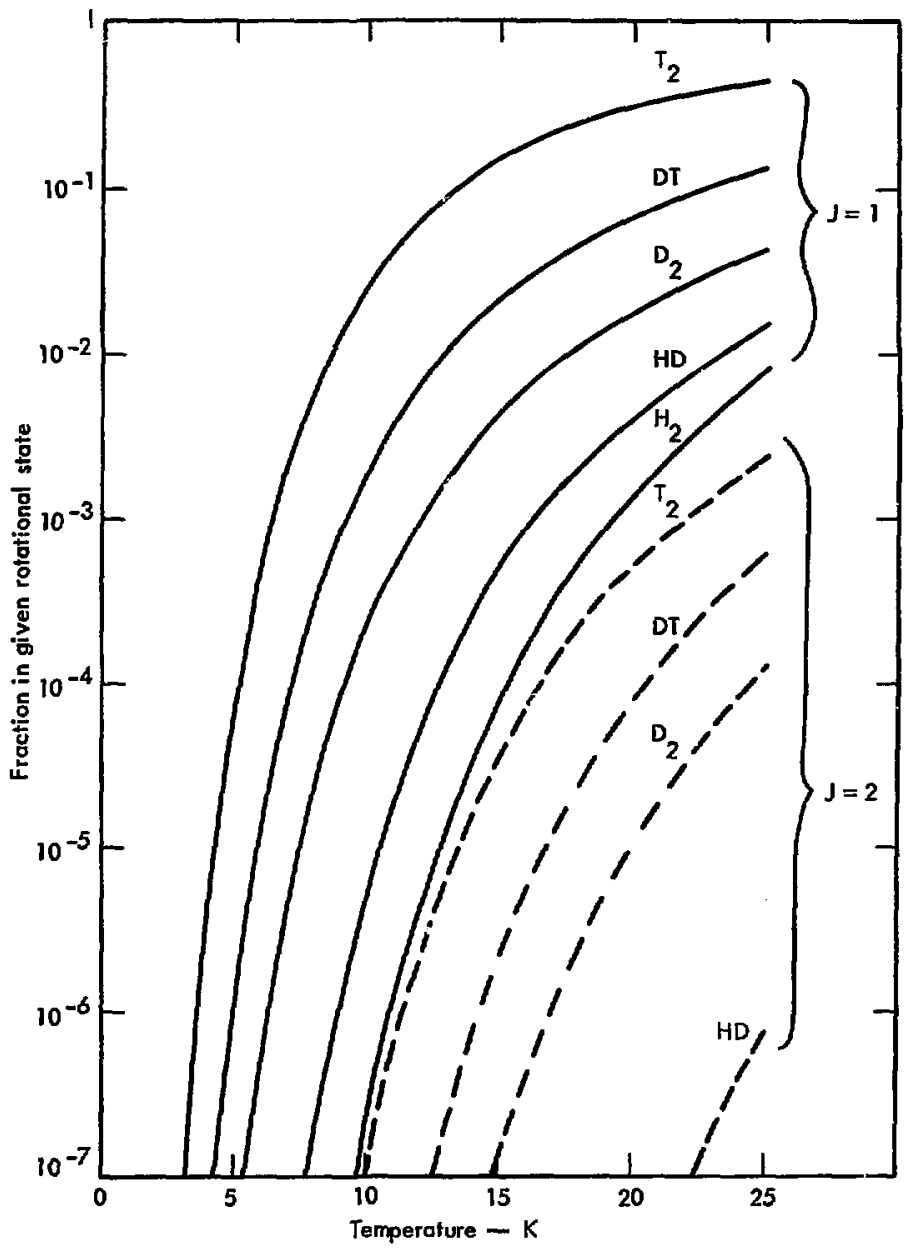

Fig. 4: Calculated rotational populations of the hydrogens from 0 to $25 \mathrm{~K}$. The $\mathrm{J}=$ I line may be considered to represent antisymmetric hydrogen. 


\section{Rotational Heat Capacity}

Rotational heat capacities and energies* may be calculated from the partition functions of the previous section. We may calculate results for a specific J-level, for the symmetric or antisymmetric sets of terms, or for all $\mathrm{J}$-levels summed together.

The rotational energy, $E_{R}$, is the product of energy jumps to a particular level times the fractional population of that level, sumed over all levels. This is

$$
E_{R}=\sum_{J=0}^{\infty} \Delta E_{J} \cdot c_{J}=R^{2} \frac{1}{Q_{R}} \frac{d Q_{R}}{d T} .
$$

The corresponding heat capacity is

$$
C_{R}=\frac{2 E_{R}}{d T} \text {. }
$$

We shall use the three-term partition function of Eq. (12) for the temperatures 0 to $25 \mathrm{~K}$.

Substituting Eq. (12) into Eq. (13), we obtain the three term, equilibrium internal energy

$$
E_{R}=R \theta_{R}\left\{\frac{6 g_{1} \exp \left(-\frac{2 \theta_{R}}{T}\right)+30 g_{2} \exp \left(-\frac{6 \theta_{R}}{T}\right)}{g_{0}+3 g_{1} \exp \left(-\frac{2 \theta_{R}}{T}\right)+5 g_{2} \exp \left(-\frac{6 \theta_{R}}{T}\right)}\right\}
$$

The equilibrium heat capacity, $c_{R}$, is, from Eq. (14)

$$
c_{R}=R\left(\frac{\theta_{R}}{T}\right)^{2}\left\{\begin{array}{l}
12 g_{0} g_{1} \exp \left(-\frac{2 \theta_{R}}{T}\right)+180 g_{0} g_{2} \exp \left(-\frac{6 \theta_{R}}{T}\right) \\
+240 g_{1} g_{2} \exp \left(-\frac{8 \theta_{R}}{T}\right) \\
{\left[g_{0}+3 g_{1} \exp \left(-\frac{2 \theta_{R}}{T}\right)+5 g_{2} \exp \left(-\frac{6 \theta_{R}}{T}\right)\right]^{2}}
\end{array}\right\} .
$$

*We use the word "energy" for the result of an ideal system and "eathalpy" for a result that has been alcered for the peculiarities of an actual system. 
The results of these calculations are listed in Tables 4 and 5 . Inclusion of the third $(J \pm 2)$ term increases the $25 \mathrm{~K}$ value of $E_{R}$ for DT by $1.4 \%$ and that for $T_{2}$ by only $1.3 \%$. Thus, we may indeed consider all the hydrogens below $25 \mathrm{~K}$ to be essentially a mixture of the $\mathrm{J}=0$ and $\mathrm{J}=1$ states.

We see, further, that equilibrium rotational effects will not affect the heat capacity data of Fig. 2, which is attributed to the crystal lattice. The worst possible case would be $2 \% \mathrm{~J}=1$ (it is supposed to be "zero") $\mathrm{D}_{2}$ at the highest temperature, $18.7 \mathrm{~K}$. From Table 5, we see thłs leads to 0.05 $(2.5 \times 0.02) \mathrm{J} /$ mole- $K$ or only $0.4 \%$ change in the low-temperature heat capacity constant, $A_{L}$, at $18.7 \mathrm{~K}$.

However, $\mathrm{H}_{2}, \mathrm{D}_{2}$, and $\mathrm{T}_{2}$ may not be in equilibrium states. They may instead be trapped with the wetastable symmetric-antisymetric combination of a higher temperature. The energles involved may be quickly estimated from a consideration of the $J=0$ and $J=1$ energy levels [neglect the third term in Eq. (12)]. The energy of the ground state is zero. The total rotational energy is that of the $J=1$ state multiplied by the fraction of molecules, $c$, in that state. Freezing in this energy at low temperature is equivalent to setting $\mathrm{T}+\infty$. All exponential terms equal ode. Then the metastable rotational energy, $E_{R}^{m}$, of a fraction $c$ of $J=1$ molecules would be

$$
\mathrm{E}_{\mathrm{R}}^{\mathrm{m}}=\mathrm{cR} \theta_{\mathrm{R}}\left(\frac{6 \mathrm{~g}_{1}}{\mathrm{~g}_{0}+3 \mathrm{~g}_{1}}\right) \text {. }
$$

For $\mathrm{H}_{2}$ through $\mathrm{T}_{2}$, the term $\left(6 \mathrm{~g}_{2} / g+3 \mathrm{~g}_{2}\right)$ has the values $1.8,1.5,1.2$, 1.5, and 1.8, summarized with other pertinent values in Table 3 . We multiply these by the proper rotational constants to get total (1.e., $c=1) \mathrm{E}_{\mathrm{R}}^{\mathrm{ma}}$ energies of $1310,819,437,458$, and $437 \mathrm{~J} / \mathrm{mole}$. The $\mathrm{HD}$ and DT values are not needed because these species deexcite Instantly with a change of temperature. We include the values only for compartson. The most likely values of $c$ to be used are those representing the initial state at room temperature; 1.e., normal hydrogen, with $c=0.75$.

The corresponding two-level heat capacity, representing a fraction $c$ of metastably cooled $\mathbf{J}=1$ species, is

$$
c_{R}^{m}=c R\left(\frac{\theta_{R}}{T}\right)^{2} \frac{12 g_{0} g_{1}}{\left(g_{0}+3 g_{1}\right)^{2}} \rightarrow 0,
$$


Table 4. Equilibrium rotational energy and total metastable energy of the hydrogens. Calculated from a three-term partition function.

\begin{tabular}{|c|c|c|c|c|c|}
\hline \multirow[t]{2}{*}{$\begin{array}{l}\text { Temperature } \\
\qquad(\mathrm{K})\end{array}$} & \multicolumn{5}{|c|}{$\begin{array}{l}\text { Equilibrium rotational energy, } E_{R} \\
\text { (J/mole) }\end{array}$} \\
\hline & $\mathrm{H}_{2}$ & HD & $\mathrm{D}_{2}$ & DT & $\mathrm{T}_{2}$ \\
\hline 2 & $1 \times 10^{-34}$ & $1 \times 10^{-25}$ & $1 \times 10^{-16}$ & $2 \times 10^{-13}$ & $9 \times 10^{-10}$ \\
\hline 4 & $1 \times 10^{-15}$ & $2 \times 10^{-11}$ & $3 \times 10^{-7}$ & $2 \times 10^{-5}$ & $2 \times 10^{-3}$ \\
\hline 6 & $3 \times 10^{-9}$ & $1 \times 10^{-6}$ & $5 \times 10^{-4}$ & $9 \times 10^{-3}$ & 0.26 \\
\hline 8 & $4 \times 10^{-6}$ & $2 \times 10^{-4}$ & $2 \times 10^{-2}$ & 0.19 & 2.9 \\
\hline 10 & $3 \times 10^{-4}$ & $6 \times 10^{-3}$ & 0.17 & I. 2 & 12.4 \\
\hline 12 & $6 \times 10^{-3}$ & $6 \times 10^{-2}$ & 0.74 & 4.0 & 31.5 \\
\hline 13.80 & $4 \times 10^{-2}$ & 0.24 & 1.9 & 8.8 & 56.2 \\
\hline 13.96 & $5 \times 10^{-2}$ & 0.27 & 2.1 & 9.4 & 58.5 \\
\hline 16 & 0.23 & 0.89 & 4.5 & 18.1 & 92.2 \\
\hline 16.60 & 0.35 & 1.2 & 5.5 & 21.2 & 102 \\
\hline 18 & 0.78 & 2.2 & 8.3 & 29.5 & 126 \\
\hline 18.7 & 1.1 & 2.9 & 10.0 & 34.1 & 138 \\
\hline 19.7 & 1.8 & 4.2 & 12.6 & 41.2 & 154 \\
\hline 20 & 2.1 & 4.6 & 13.4 & 43.4 & 159 \\
\hline 20.6 & 2.7 & 5.6 & 15.3 & 48.1 & 169 \\
\hline 21 & 3.1 & 6.2 & 16.5 & 50.2 & 175 \\
\hline 22 & 4.6 & 8.3 & 19.9 & 59.3 & 190 \\
\hline 23 & 6.5 & 10.7 & 23.5 & 67.6 & 204 \\
\hline 24 & 8.9 & 13.6 & 27.5 & 76.2 & 216 \\
\hline \multirow[t]{3}{*}{25} & 11.8 & 16.8 & 31.6 & 84.8 & 229 \\
\hline & \multicolumn{5}{|c|}{$\begin{array}{c}\text { Total metastable energy, } E_{R}^{m} \\
(J / m o l e)\end{array}$} \\
\hline & 1310 & 819 & 437 & 458 & 437 \\
\hline
\end{tabular}


Table 5. Equilibrium rotational heat capacity of the hydrogens. Calculaced from a three-term partition function.

\begin{tabular}{|c|c|c|c|c|c|}
\hline \multirow[t]{2}{*}{$\begin{array}{c}\text { Temperature } \\
\text { (K) }\end{array}$} & \multicolumn{5}{|c|}{$\begin{array}{l}\text { Equilibrium rotational heat capacity, } C_{R} \\
\text { (J/mole-K) }\end{array}$} \\
\hline & $\mathrm{H}_{2}$ & $H \boldsymbol{b}$ & $\mathbf{b}_{2}$ & DT & $\mathbf{r}_{2}$ \\
\hline 2 & $6 \times 10^{-33}$ & $3 \times 10^{-24}$ & $2 \times 10^{-15}$ & $4 \times 10^{-12}$ & $1 \times 10^{-8}$ \\
\hline 4 & $1 \times 10^{-14}$ & $1 \times 10^{-10}$ & $2 \times 10^{-6}$ & $9 \times 10^{-5}$ & $7 \times 10^{-3}$ \\
\hline 6 & $1 \times 10^{-8}$ & $4 \times 10^{-6}$ & $1 \times 10^{-3}$ & $2 \times 10^{-2}$ & 0.42 \\
\hline 8 & $1 \times 10^{-5}$ & $5 \times 10^{-4}$ & $3 \times 10^{-2}$ & 0.22 & 2.7 \\
\hline 10 & $6 \times 10^{-4}$ & $8 \times 10^{-3}$ & 0.15 & 0.87 & 7.0 \\
\hline 12 & $7 \times 10^{-3}$ & $5 \times 10^{-2}$ & 0.45 & 2.0 & 11.9 \\
\hline 13.80 & $4 \times 10^{-2}$ & 0.17 & 0.88 & 3.4 & 15.2 \\
\hline 13.96 & $4 \times 10^{-2}$ & 0.18 & 0.92 & 3.5 & 15.5 \\
\hline 16 & 0.16 & 0.46 & 1.5 & 5.0 & 17.1 \\
\hline 16.60 & 0.22 & 0.57 & 1.7 & 5.5 & 17.2 \\
\hline 18 & 0.42 & 0.89 & 2.2 & 6.4 & 17.0 \\
\hline 18.7 & 0.57 & 1.1 & 2.5 & 6.8 & 16.6 \\
\hline 19.7 & 0.82 & 1.4 & 2.8 & 7.3 & 16.1 \\
\hline 20 & 0.91 & 1.5 & 2.9 & 7.5 & 15.9 \\
\hline 20.6 & 1.1 & 1.7 & 3.1 & 7.7 & 15.4 \\
\hline 21 & 1.2 & 1.9 & 3.2 & 7.9 & 15.2 \\
\hline 22 & 1.6 & 2.2 & 3.5 & 8.2 & 14.4 \\
\hline 23 & 2.1 & 2.6 & 3.8 & 8.4 & 13.5 \\
\hline 24 & 2.7 & 3.1 & 4.1 & 8.7 & 12.7 \\
\hline 25 & 3.3 & 3.5 & 4.3 & 8.8 & 12.0 \\
\hline
\end{tabular}

because when $T \rightarrow \infty, c_{R}^{m} \rightarrow 0$. Thus, we have no rotational heat capacity due to metastable states at low teinperature. This is because the states are frozen as though they were at an infinite temperature. 


\section{Deseription of Qundrupolar Sublevets in Solid Hydrogen}

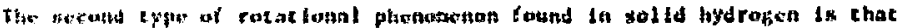

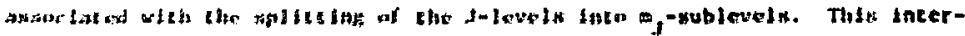

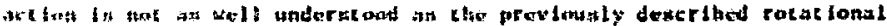

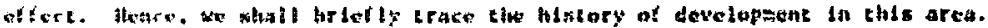

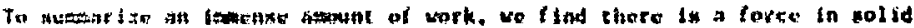

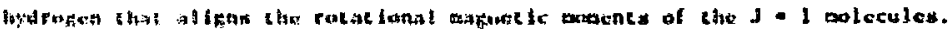

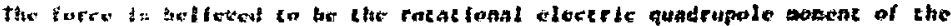

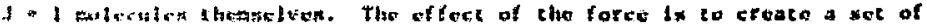

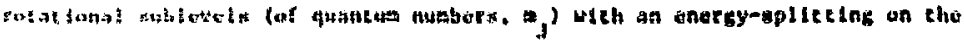

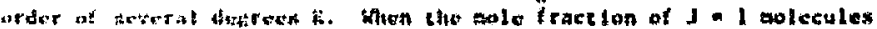

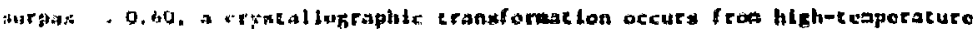

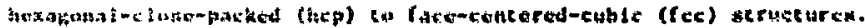
Flater

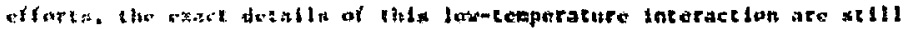
Bashout?.

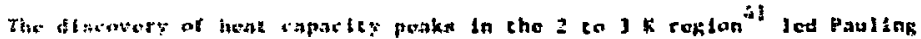

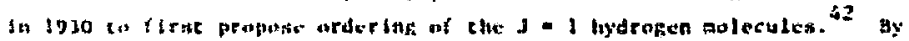

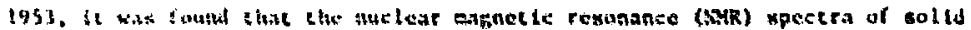

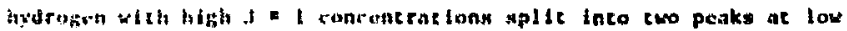

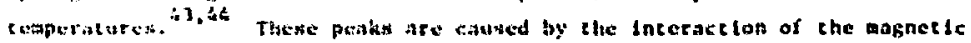
difoles of the bytrogen nuclet in the $H_{2}$ molocule. Ac lou cemperatures.

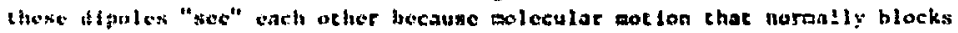

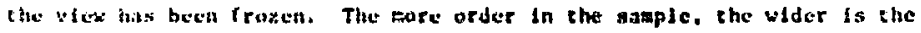
splite fing of the twis sMk peaks. It was posculaced (but is not belfeved (odily) that an internill crystal fleld separaces che $\mathrm{J}$ - $1 \mathrm{H}_{2}$ colecules inco

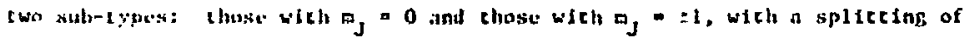
4 co 5 k. The forater s, value represents che ground state, the later the excited state. The applicallon of the de magnet fe ficid fer xar splics the

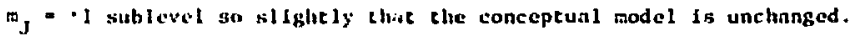

It 1954, heat capacicy studies of 0.66 and $0.74 \mathrm{~J}-\mathrm{I} \mathrm{H}_{2}$ showed large spikes at 1.3 and $1.6 \mathrm{~K}$ (bu: not at $0.56 \mathrm{~J}=1$ down to $1.15 \mathrm{~K}$ ). 15 Suct splkes, called lambda-points because of cheir shapes, are characteristic of orderdisorder cransitions. Such cransteions, wost comon in terro- or antiferromagnet ism, ore called "second-order" transitions. Such transitions do not have discontinulties in latent heat or spectfic volume at the tronsition 
point, but do have discontinuities in the specific heat. The degree of order diminishes as the sample is hea ed to the transition point. At the transitton poinc, the remaining order may be lost abruptly (first-kind) or gradually (second-kind). The heat capacity lambda-point usually shows a high temperature ca11. representing a hysteresis of the transition. 45 It is also interesting to note that ordered solid $\mathrm{H}_{2}$ has been described as an antiferromagnet (i.e., ordered spins but no net magnetic moment to the sample). ${ }^{46}$ Because the $\mathrm{H}_{2}$ spins involved are rotational, the result is an "ordered diamagnetism."

It is difficult to judge the onset of an order-disorder transition. The splitting of the $J=1$ states Into the two postulated substates represents a degree of rotational ordering. The $\bar{f} f 11 \mathrm{ing}$ of a finite number of these energy levels ( $1 . e$. , destroying this order) also produces a heat capacity peak and cail. Let us consider a single graund state and a doubly degenerate excited scace (1.e., two states at the sane energy) separated by an energy gop represented by the quadrupolar temperature $\theta_{Q^{*}}$ The partition function for these magnet ic sublevels, $Q_{Q}$, is

$$
Q_{Q}=1+2 \exp \left(-\frac{\theta_{Q}}{T}\right) \text {. }
$$

We may ise the general formulas of the previous section to calculate the energy and heat capacity. Only the fraction of $J=1$ molecules, $c$, gives $r$ ise to the partition function. The calculated equilibrium quadrupolar energy is

$$
E_{Q}=2 c R \theta_{Q} \frac{\exp \left(-\frac{\theta_{Q}}{T}\right)}{1+2 \exp \left(-\frac{\theta_{Q}}{T}\right)} .
$$

The calculated equilibriun quadrupolar heat capacity is

$$
C_{Q}=2 \operatorname{cR}\left(\frac{\theta_{Q}}{T}\right)^{2} \frac{\exp \left(-\frac{\theta_{Q}}{T}\right)}{\left[1+2 \exp \left(-\frac{\theta_{Q}}{T}\right)\right]^{2}}
$$

The heat capacity, $C_{Q}$, rises quickly to a peak at a $\theta_{Q} / T$ value of 2.65 , then decays in a long tall as $\mathrm{T}^{-2}$. Such a peak is called a Schottky anomaly, which is characteristic of exergy absorption by a finite number of energy levels. $39,47,48$ The two-level model, described by the Eqs. (19) to (21), is the simplest conceptual approach to rotational splittings in solid hydrogen. 
The next theoretical development, in 1955, has had the largest impact on the thowy of low-temperature heat capacity. Nakamura consfdered the inceractions botween pairs of $\mathrm{H}_{2}$ nolecules. 49 He concluded that the inceract ion between $J=0$ and $J=1$ molecules is not importan in the hep lattice (the for transformation had not yet been discovered). Of prime importance are the interactions of electric quadrupole turinents of neighboring $J=1$ hydrogen molecules. The three rotational substates $\left(m_{j}=-1,0\right.$, and +1$)$ of each tholeculd then combine to form the nine sublevels shown in Flg. 5.; The energy levels tor three interacting. $I=1$ molecules have also be en calculated. 50 Figurc 5 show's the 27-sublevel scheme of une of the configurations of the three molecules. It can be Imagined that the spectrum in a highly saturated concentrated siample of $J=1 \mathrm{H}_{2}$ may be complicated indeed.

In J965, another major step occurred rugarding the low temperature transition. Line changes in the infrared spectrum of normal $\mathrm{H}_{2}$ at $1.5 \mathrm{~K}$ were interpreted as a crystallograpblc transition. 51 Confirmation of the hcp-torec cranst ormition canse from $x-r a y$ diffraction almost immediately. $\$ 2.53$ Athough the transition is undoubtedy First order, the volume dis.ontinuit: is very small: only $0.15 \%$ upon cooling and $0.08^{\circ}$ upon warming for $\therefore 0.73$ mole irarlion $1=1$ sample. Virtually no volume change 1 s seen at $1.63 \mathrm{~J}=1$. Extrapolation to pure $J=1$ hydrogen yields less than $0.5 \%$ volume thange. In contrast, $J=1 \mathrm{H}_{2}$ at $4.2 \mathrm{~K}$ expands 1.3 vol\% $\mathrm{just}$ in converting $\mathrm{to} \mathrm{J}=0$ $\mathrm{H}_{2} \cdot 54$

Figuro 6 shows the temperatures at which the first-order crystallographic transition takes place. The transition temperature, which increases with the mole fraction of $J=1$ molecules, is higher for $D_{2}$ than for $H_{2}$; The daca is obtained from $x$-ray diffraction, ${ }^{55}$ heat capacity lambda peaks, 15,3 : and the appearance $n$ f NMR peaks. ${ }^{56}$ The hysteresis of the transition is evident from the transition temperature differences upon conling or heating. Below 0.60 mole fraction of $\mathrm{J}=1 \mathrm{H}_{2}$, no heat capacity spike is seen down to $0.2 \mathrm{~K} .57$ The first-order transition apparently only extends from mole fractions of 0.6 to $1.0 \mathrm{~J}=1$ molecules. In the hep mole-fraction region (0 to 0.6$)$, there is a second-order transition to the ordered rotational state. The peak

\footnotetext{
*Energy level temperatures instead of quadrupolar coupling constants are used to give a better physical feel for the distance between levels. However, the splittings vary with sample temperature and must be considered approximate.
} 


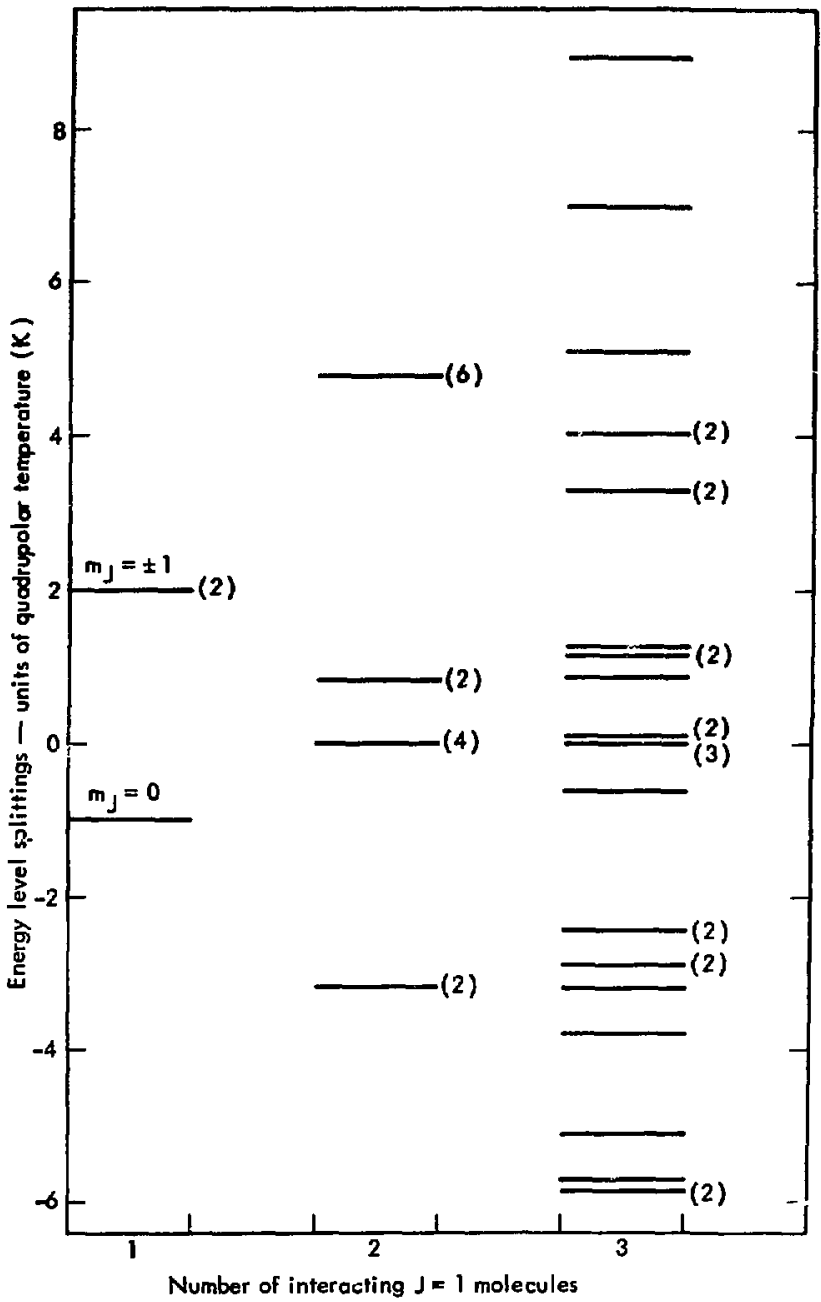

FIg. 5. Calculated quadrupolar energy sublevels. Splittings are approximate; numbers of states are within parencheses. 


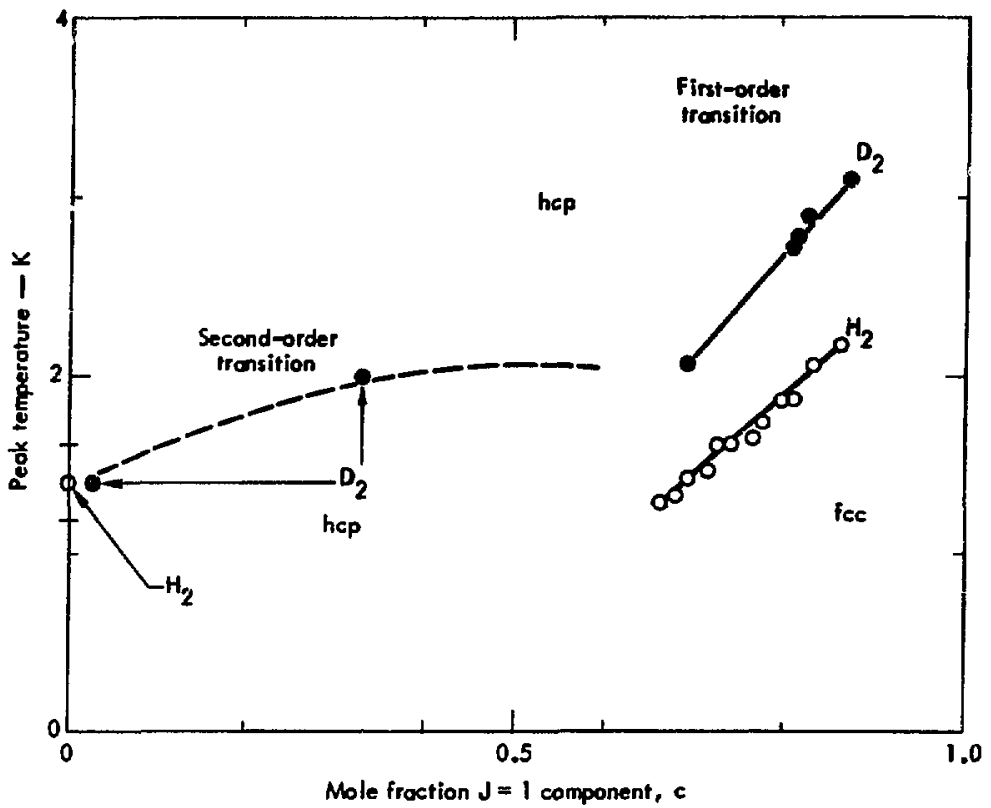

Fig. 6. Solid-solid transitions in solid $H_{2}$ and $D_{2}$.

Lemperatures of the rotational heat capacities are plotted for three samples of $0.0022,0.03$, and $0.331 \mathrm{~J}=1$ mole fractions. ${ }^{20,21,28,29}$ we presume that the second-order transition crosses over into the region of the first-order change. The means of connecting the low- and high-mole fraction regions is not shown. 


\section{Data and Interpretation for Quadrupolar Heat Capacily}

We obtalned values of $C_{Q}$ by subtracting the latctee heat capacity (found for $c=0$ ) from the total heat capacity for a biven fraction of $J=1$ component, c. Rotational heat capacity, $C_{k}$, is not a factor, as already deseribed, because $H_{2}$ and $D_{2}$ have rotaltomi populations that are metist.sbly frozen and HD values are small up to $14 \mathrm{~K}$. The calculation of $C_{Q}$ is subject to constderable error because of the subtraction of two Iirge quint it les. Figure 7 shows the most complete single .] $=1$ heat rapacity curve yot aneasured: on $0.03 \mathrm{~J}=1 \mathrm{D}_{2} \cdot 30$ There $1 \mathrm{~s}$ a peak at 1.3 to $1.4 \mathrm{~K}$ followed by a long tail. The peak temperature corresponds to an energy gap of about $3.6 \mathrm{~K}$, using the two-level model of Eq. (21). We drew a $\mathrm{T}^{-2}$ type curve through the tail points, but the spread of data was considerable.

Two other sources exist in which heat capacity peaks are measurod for $J=1$ concentrations less than the 0.60 needed to cause the hep-to-fcc transition: $0.0022 \mathrm{~J}=1 \mathrm{H}_{2}^{21,22}$ and $0.33 \mathrm{D}_{2} .^{29}$ All three peal temperatures are on the left side in Fig. 6. The remnants of this peak also appear in

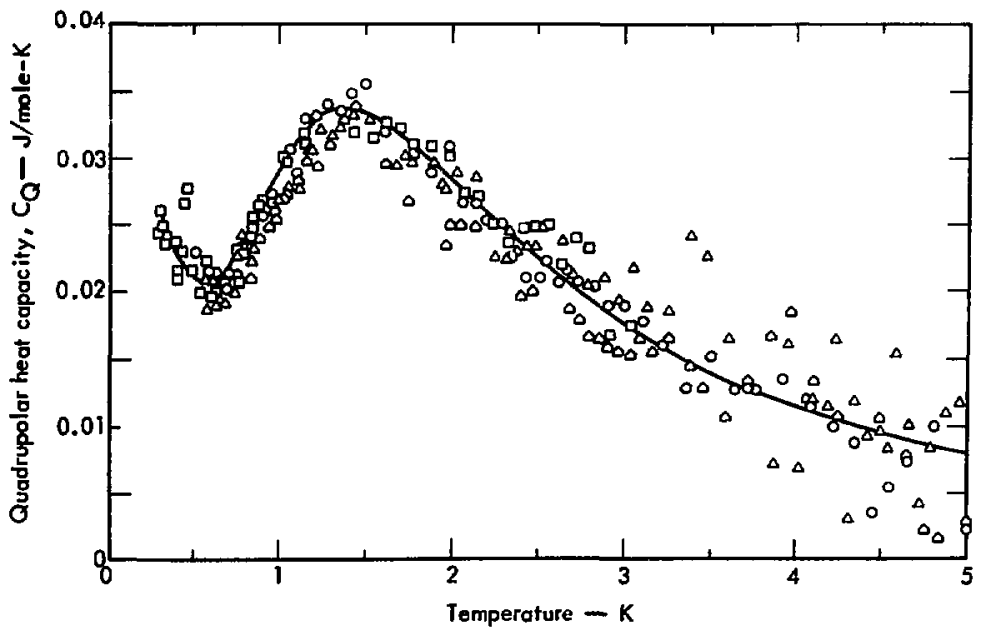

FIg. 7. Quadrupolar heat capacity of $0.03 \mathrm{~J}=1 \mathrm{D}_{2^{*}}{ }^{33}$ 
the lin temperature portion ot Fig. 2, whith we cosed to deflve the "zero"

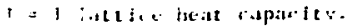

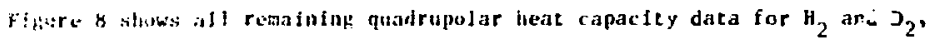
buth inuve anc below the $0.60 .1=1$ mark that indicates the hep-to-f ce fratisition. This ditat, which is above $2 \mathrm{~K}$, represents only the cails. The i!. dita jurms poud ptuts 15,17 that derline linearly with temperature - not as $t^{22}$. The amplitude is directly proport tonal to $c$. The $D_{z}$ data is from mony sources; ${ }^{16,26-29}$ and is quite scattered. It too is closest to being a lusi-liun of, but the temperature functionality cannot be obtained.

$A$ inplet. : cmierature spectrum of the quadrupolar heat capactiv has not beell musur.d. Nevertheless, it ls posstble to roughly extrapolate known

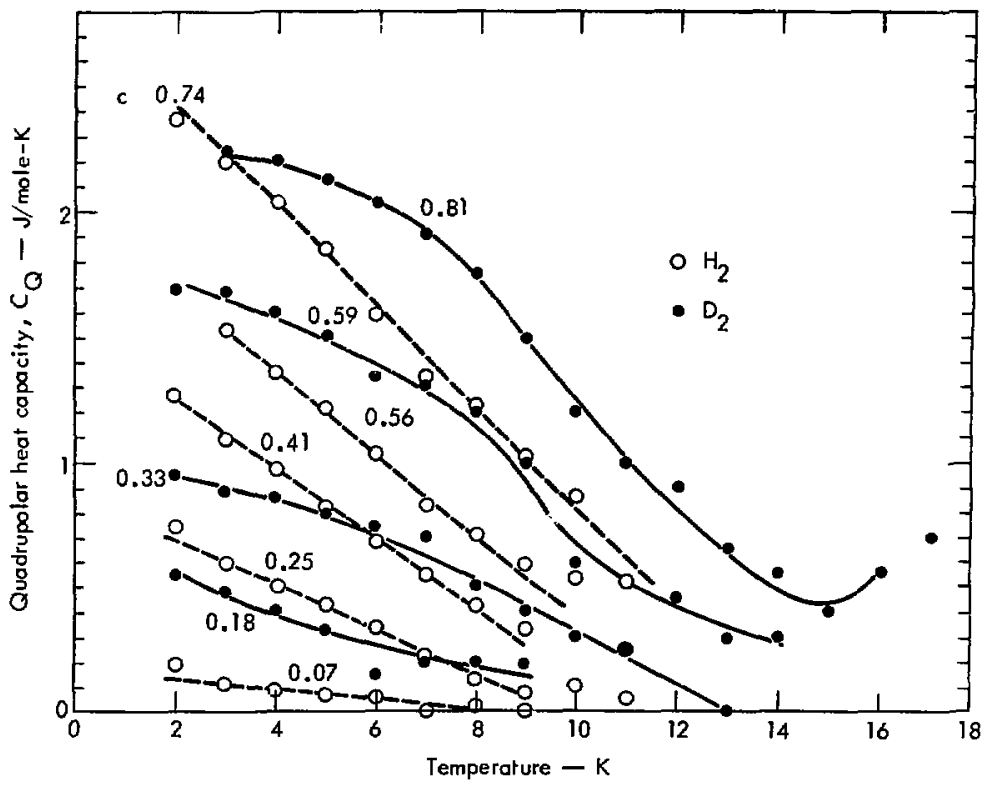

F1g. 8. Quadrupolar heat capacity of solid $\mathrm{H}_{2}$ and $\mathrm{D}_{2}$. The mole fraction $\mathrm{J}=1$ component, $\mathrm{c}$, is listed. 
curves elther to $0 \mathrm{~K}$ or through the remainder of their talls. The curves can be integrated to obtain the quadrupolar enthalpy, ${ }_{Q}$. We have carried this our for all avallable $\mathrm{H}_{2}, \mathrm{D}_{2}$ and $\mathrm{H}_{2}-\mathrm{D}_{2}$ mixture data. $15,21,22,29,30$

Figure 9 shows the results, which necessarily contain considerable uncertainty. All points but one fall near the line; only the very end of the line corrasponds to the hcp-to-fce transformation range. It appears that the secor, l-order transition may Indeed extend down to the lowest measured values of $c$. The enthalpy, $\mathrm{H}_{\mathrm{J}}$, is not directly proportional to $\mathrm{c}$ as expected from the two-level model and the $\mathrm{H}_{2}$ data of Fig. 8 , which spans a much staller range of $c$. We fit ali the data, covering $c$ values of 0.0022 to 0.81 , in Fig. 9 to the empirical equation

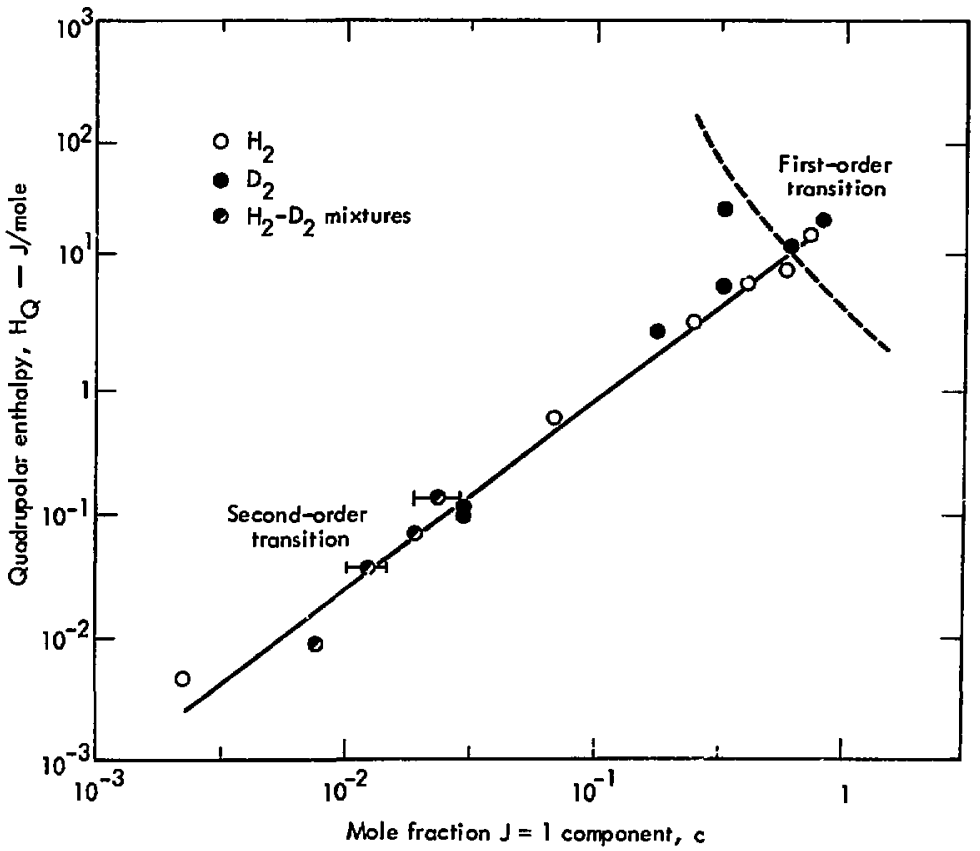

F18. 9. Quadrupolar enthalpy of solid $\mathrm{H}_{2}$ and $\mathrm{D}_{2^{*}} 12,14-19,22-26$ 


$$
H_{Q} 225 c^{1.5 \pm 0.1}
$$

All data, whether $\mathrm{H}_{2}, \mathrm{D}_{2}$, or $\mathrm{H}_{2}-\mathrm{D}_{2}$ mixtures, fit Eq. (22).

It is also true that $\mathrm{H}_{Q}$ and $\mathrm{C}_{Q}$ for $\mathrm{H}_{2}-\mathrm{D}_{2}$ mixtures are equivalent, within error, to 1 inear combinations of the values of the pure components. $19,20,22$

The actual theory of the quadrupolar heat capacity is much more complicated than the two-level model presented above. Roberts and Daunt 22 use the ninesublevel model of pairs of $\mathrm{J}=1$ molecules ${ }^{49}$ and the 27 -sublevel model of three $\mathrm{J}=1$ molecules. 50 They proceed via the partition function to the "pairs" and "triples" quadrupolar heat capacities. They overlay these combinations in various proportions and with different quadrupolar temperatures until a fit is achieved with the data (e.g., Fig. 7). The addition of a series of heat capacity terms, each decaying approximately as $T^{\mathbf{- 2}}, \because$ ields an overall $c_{j}$ tail that looks closer to being linear.

Roberts and Daunt also conclude, for their 0.0022 and $0.03 \mathrm{~J}=1$ samples, that "pair" interactlons with splittings of about $0.9 \mathrm{~K}$ almost totally dominate the heat capacity. They assume that no crystal field exists in solid hydrogen strong enough to cause significant splitting of the levels of a single J = 1 molecule. The effect of a dominant "pair" mechanism at low $J=1$ concentrations is to make the quadrupolar enthalpy, ${ }_{Q}$, proportional to $c^{2}$ ("triples" would be proportsonal to $c^{3}$ ). This may be compared with the 1.5 power of $c$ found by us In Fig. 9. Finally, they conclude that the $\mathrm{J}=1$ moments are not"frozen-In" for solid H $H_{2}$ but migrate by "rotation diffusion" to form more pairs than expected by chance.

In their next work, Roberts and Daunt extended their tempe:ature range down to $0.3 \mathrm{~K}$ and found the low temperature heat capacity rise shown in Fig. 7. ${ }^{30} \mathrm{Tt}$.ay feel this $\mathrm{rise}$ is part of a lower cemperature peak, although they were not able to cool the sample enough to locate the sumit. They interpret this proposed peak as being caused by $\mathrm{J}=1$ pairs with molecules at next-nearest neighhor locations. The added distance between molecules reduces the quadrupolar coupling to about $0.2 \mathrm{k}$. Wich energy levels closer together, the peak occurs at a lower temperature. This mechanism produces an enthalpy proportional to $\mathrm{c}$ at low $\mathrm{J}=1$ concentrations. Also, the pairs model nas been applied to $0.01 \mathrm{~J}=1 \mathrm{H}_{2}$ and $\mathrm{D}_{2}$ impurities in solid $\mathrm{HD}{ }^{25}$ A nearest neighbor model is fitted by adjusting $c$ to 0.76 and the quadrupolar coupling constant to $0.72 \mathrm{~K}$. The above mentioned quadrupolar splittings 
agree with values of 0.8 to $1.1 \mathrm{~K}$ obtained $\mathrm{from}$ an independent 1 ine of theoretical calculation. 58

A final complication concerns the energy level splitting of isolated $\mathrm{J}=1$ molecules in the $\mathrm{J}=0$ matrix. NRR measurements indicated that nonquadrupolar fields cause splittings of only 0.01 to $0.02 \mathrm{~K} .59,60$ this led Roberts and Daunt to excluce single $J=1$ molecules from their heat capacity analysis. 22 A recent NMR study finds a crystal field splitting of $0.6 \mathrm{~K}$, the same order of magnitude as the quadrupolar effect. 61 It appears that the theory of the $J=1$ heat capacity is not yet settled.

To summarize, we find no constistent description of the data possible and the theorles complex and incomplete. We shall, therefore, summarize the findings with a simpler, empirical formula. We shall combine the two-level model of Eqs. (19) to (21) with the experimental enthalpy description of Eq. (22). In doing this, we will take the internal energy of a perfect gas of particles with individual quadrupolar interactions and convert it to á real enthalpy representing the solid. We propose the form

$$
H_{Q} 22 c^{1.5}{ }^{R \theta_{Q}}\left[\frac{\exp \left(-\frac{\theta_{Q}}{T}\right)}{1+2 \exp \left(-\frac{\theta_{Q}}{T}\right)}\right] \text {, }
$$

where the only change to Eq. (20) is to substitute 1.5 instead of 1.0 as the power of $c$. The equation does not explicitly account for the possible lowtemperature peak In Fig. 7. However, the amount of energy in such lowtemperature peaks must be smill. At high temperatures, the energy levels in Eq. (23) become filled, the enthalpy becomes constant, and the exponents equal one. We find that Eq. (23) for $T+\infty$ produces enthalpies in agreement with Eq. (22) if we set $\theta_{Q}=4.5 \mathrm{~K}$. This is like saying that the temperature peak of the quadrupolar heat capacity is always at $1.7 \mathrm{~K}$. Figure 6 shows that this is approximately true for c values from 0 to 0.4 , which covers the range expected in equilibrated hydrogen below $25 \mathrm{~K}$. The enthalpy becomes

$$
H_{Q} \simeq 74.8 c^{1.5}\left\{\frac{\exp (-4.5 / T)}{1+2 \exp (-4.5 / T)}\right\} \text {. }
$$

and the heat capacity is

$$
C_{Q} \approx 337 \frac{c^{1.5}}{T^{2}} \frac{\exp (-4.5 / T)}{[1+2 \exp (-4.5 / T)]^{2}} \text {. }
$$


Equations (24) and (25) fit both the expertmental $\mathrm{H}_{2}$ and $\mathrm{D}_{2}$ data fairly well. We shall postulate thetr uso to $\mathrm{HD}, \mathrm{DT}$, and $\mathrm{T}_{2}$ as well. The equations give reasonable answers even for high $c$ values in the hcp $\rightarrow$ fcc transformation region. However, it is not possible co relate our $1.7 \mathrm{~K}$ fixed-temperature peak to the higher temperatures of the crystallographic transformation. We have calculated Egs. (24) and (25) from 1 to $20 \mathrm{~K}$ for unspecified values of $\mathrm{c}$. The results are in Table 6 and may be applied, based on the similarity of $\mathrm{H}_{2}$ and $\mathrm{D}_{2}$ data, to all the isotopes.

Table 6. Quadrupolar enthalpy and neat capacity of solfd hydrogen. Calculated from Eqs. (24) and (25); $\mathrm{HD}, \mathrm{DT}$, and $\mathrm{T}_{2}$ data are complete estimates (in parentheses).

\begin{tabular}{|c|c|c|c|c|c|}
\hline \multirow[t]{2}{*}{$\begin{array}{l}\text { Temperature } \\
\text { (K) }\end{array}$} & \multicolumn{2}{|c|}{ For $c=1^{a}$} & \multicolumn{3}{|c|}{$\mathrm{H}_{\mathrm{Q}}$ at equilibrium } \\
\hline & $\underset{\text { (J/mole })}{{ }_{\mathrm{H}}}$ & ${ }_{(\mathrm{J} / \mathrm{mole}}^{\mathrm{C}_{\mathrm{Q}}}$ & $\mathrm{D}_{2}$ & (DT) & $\left(T_{2}\right)$ \\
\hline 1 & 0.81 & 3.6 & 0 & $(0)$ & (0) \\
\hline 1.7 & 4.6 & 6.3 & 0 & (0) & (D) \\
\hline 2 & 6.5 & 6.1 & 0 & (0) & $(0)$ \\
\hline 3 & 11.5 & 4.0 & 0 & (0) & (0) \\
\hline 4 & 14.7 & 2.5 & 0 & (0) & $(0)$ \\
\hline 6 & 18.2 & 1.2 & 0 & $(0)$ & $(0)$ \\
\hline 8 & 19.9 & 0.66 & 0 & (0) & (0) \\
\hline 10 & 21.0 & 0.42 & 0 & (0) & $(0.1)$ \\
\hline 12 & 21.6 & 0.29 & 0 & $(0)$ & $(0.4)$ \\
\hline 14 & 22.1 & 0.21 & 0 & $(0)$ & $(1.1)$ \\
\hline 16 & 22.5 & 0.16 & 0 & $(0.2)$ & $(2.2)$ \\
\hline 18 & 22.8 & 0.12 & 0.1 & $(0.4)$ & $(3.5)$ \\
\hline 20 & 23.0 & 0.10 & 0.1 & $(0.7)$ & $(5.0)$ \\
\hline$n$ & 24.9 & 0 & - & - & - \\
\hline
\end{tabular}

${ }^{a}$ For other values of $J=1$ component, multiply by $c^{1.5}$. 
To better gauge the Importance of these properties, let us calculate the actual equilibrium heats at the various temperatures, The heats per mole will then be multiplied by the equilibrium concentration of the $J=1$ species, which, calculated for just two levels, is

$$
c=\frac{3 g_{1} \exp \left(-\frac{2 g_{R}}{T}\right)}{g_{0}+3 g_{1} \exp \left(-\frac{2 \theta_{R}}{T}\right)}
$$

where $g_{0}$ and $g_{1}$ values are 11sted in Table 3 . The quadrupolar equilibrium enthalpies and heat capacities up to $20 \mathrm{~K}$ axe shown for $\mathrm{D}_{2}$, DT, and $\mathrm{T}_{2}$ in Table 6. Only $\mathrm{T}_{2}$ has an appreciable amount of $\mathrm{J}=1$ spectes to produce much enthalpy. But, at $20 \mathrm{~K}$, where the $\mathrm{J}=1$ levels begin to $\mathrm{fill}$, the m $\mathrm{J}_{\text {-sublevels }}$ are saturated and the heat capacity approaches zero. We see that the quadrupolar heat capacities are so small that they may be neglected for all equilibrium hydrogen.

If $\mathrm{H}_{2}$ or $\mathrm{D}_{2}$ is quenched and is in a metastable rotational state at some cryogenic temperature, there w1ll be a metastable quadrupolar enthalpy, ${ }^{m}{ }_{Q}$, and heat capacity, $\mathrm{c}_{\mathrm{Q}^{\mathrm{m}}}^{\mathrm{m}}$. These do not require new equations, as with the metastable rotational case. We may use Eqs. (24) and (25) with the proper metastable value of $c$. This value, in most experiments, will be the normal, room temperature figure. Because the metastable quadrupolar enezgy is frozen, we expect a zero heat capactity

$$
c_{Q}^{m}=0
$$

\section{Basic Theory of Thermal Conductivity in Solids}

Thermal conductivity does not separate into the lattice, rotational, and quadrupolar mechanisns found with heat capacity and enthalpy. This is because even for $J=0$ hydrogen, there are two mechanisms in combination. If we add $J=1$ hydrogen, we do not know whether there are st 111 just two mechanisms or more. For the sake of simplicity, we shall assume two mechanisms, to be described as a function of $c$, the fraction of $J=1$ hydrogen: the crystallite size mechanism at low temperatures and the Umklapp mechanism at higher temperatures. 
lotal thermal conductivity, $\mathrm{K}_{S}$, is a sum of the crystallite conductivity, $k_{d}$, and the Umklapp conductivity, $k_{\mathcal{~}}$, according to

$$
\frac{1}{\mathrm{~K}_{\mathrm{S}}}=\frac{1}{\mathrm{~K}_{\mathrm{d}}}+\frac{1}{\mathrm{~K}_{\mathrm{d}}} \text {. }
$$

Heat is carried through a crystal, mostly by phonons. These are crystal lattice vibrations, which move like small bundles of energy. As heat is put into a sample and temperature increases, phonons are created that carry energy from the hot to the cold zone.

At low temperatures, not only are there very $f$ ew phonons but they do not get in each other's way. Instead, they travel a11 the way across a crystallite (or single crysta1) until they hit the edge and reflect. This colliston with the wall sets up a bound to the thermal conductivity. We may consider the phonons to be like a gas, where the phonon "quasiparticles" have a mean free path determined by the crystallite size, d. From the kinetic theory of gases, we have the crystallite thermal conductivity, $K_{S}$, of

$$
K_{\mathrm{d}}=\frac{1}{3} \mathrm{C}_{\mathrm{L}} \rho_{\mathrm{S}} \text { ud, }
$$

where $C_{1}$ is the crystal lattice heat capaclty, $\rho_{S}$ the solid density, and $u$ the speed of sound in the solid. 62

The product $\mathrm{C}_{L} \rho_{S}$ is the crystal lattice heat capacity per unit volume. Equation (29) assumes that rotational and quadrupolar energies are not available to the phonons.

The only highly temperature-dependent quantity in $\mathrm{Eq}$. (29) is $\mathrm{C}_{\mathrm{L}}$, which increases as $T^{3}$ [Eq. (4)]. Hence, we expect a sharply rising thermal conductivity at low temperatures.

As the temperature continues to rise, ever more phonons are produced until they collide with one another more than with the walls of the crystallite. This becomes the dominant mechanism. The thermal conductivity decreases with temperature because of the ever higher production of phonons. At an intermediate temperature, where the two mechanisms are of equal strength, we find a thermal conductivity peak.

Umklapp (or U-) processes are phonon-phonon collisions that reduce the phonon mean free path with increasing temperature. A ready analogy is a pipe full of gas, closed at both ends. ${ }^{62}$ One end is hot, the other cold. By molecular collisions, energy passes from the hot to the cold end. Yet, there 
is no mass transfer of gas molecules from one end to the other. Here the analogy ends because the gas will have a higher density at the cold end.

Phonons, however, are vibrational bundles of lattice energy that are created by heating the crystal. Thelr density and collision irequency will be higher at the hot end of a crystal. But, in analogy with the gas, although energy flows from the hot end of a crystal to the cold end, there is no mass transfer of phonons. Each colliston of two phonons results in one moving forward and one bouncing backward - then there is no net movement of phonons. This collision is much like a chemical or cyclotron particle reaction in that a threshold energy of $k \theta_{\mathrm{D}} / 2$ per collision is required, where $k$ is Boltzmann's constant. The number of phonons and the avallability of the necessary threshold energy increase with temperature, so the rate of limklapp collisions is a function of $\exp \left(-\epsilon_{D} / 2 T\right)$, where $\theta_{D}$ is the Debye temperature. The Umklapp phonon mean free path, $\lambda_{U}$, is the Inverse of this; $1 . e$. , it decreases exponentially with temperature. ${ }^{63}$ We use a higher temperature variant of Eq. (29) - again, the kinetic gas equation

$$
\mathrm{K}_{\mathrm{t}}=\frac{\mathrm{I}}{3} \mathrm{c}_{\mathrm{L}} \rho_{\mathrm{S}} \mathbf{u} \lambda_{\mathrm{u}}
$$

so that we obtain tae functionality

$$
k_{U} \sim T^{3} \exp \left(\frac{\theta_{D}}{2 T}\right) \text {. }
$$

In practice, actual substances have a figure of 2 to 3 for the denominator of the exponent.

\section{Experimental Thermal Conductivity of Solid Hydrogen}

Solid hydrogen thermal conductivity data is nowhere as large as that for heat capacity. The literature consists of four papers with extensive data, 64-6? four with fragmentary data, ${ }^{68-71}$ and two purely theoretical works. 72,73 Most of the data appear In the recent NBS survey ${ }^{74}$ and are plotted in Fig. 10 .

Looking at Fig. 10, we see that the thermal conductivity of "zero" $J=0$ hydrogen forms a peak just below liquid helium temperature. The conductivity then drops two decades and starts to flatten out at the triple point. The effect of adding rotational energy is to ilatten out the peak, with the peak temperature increasing with increasing $J=1$ component. Most data are 


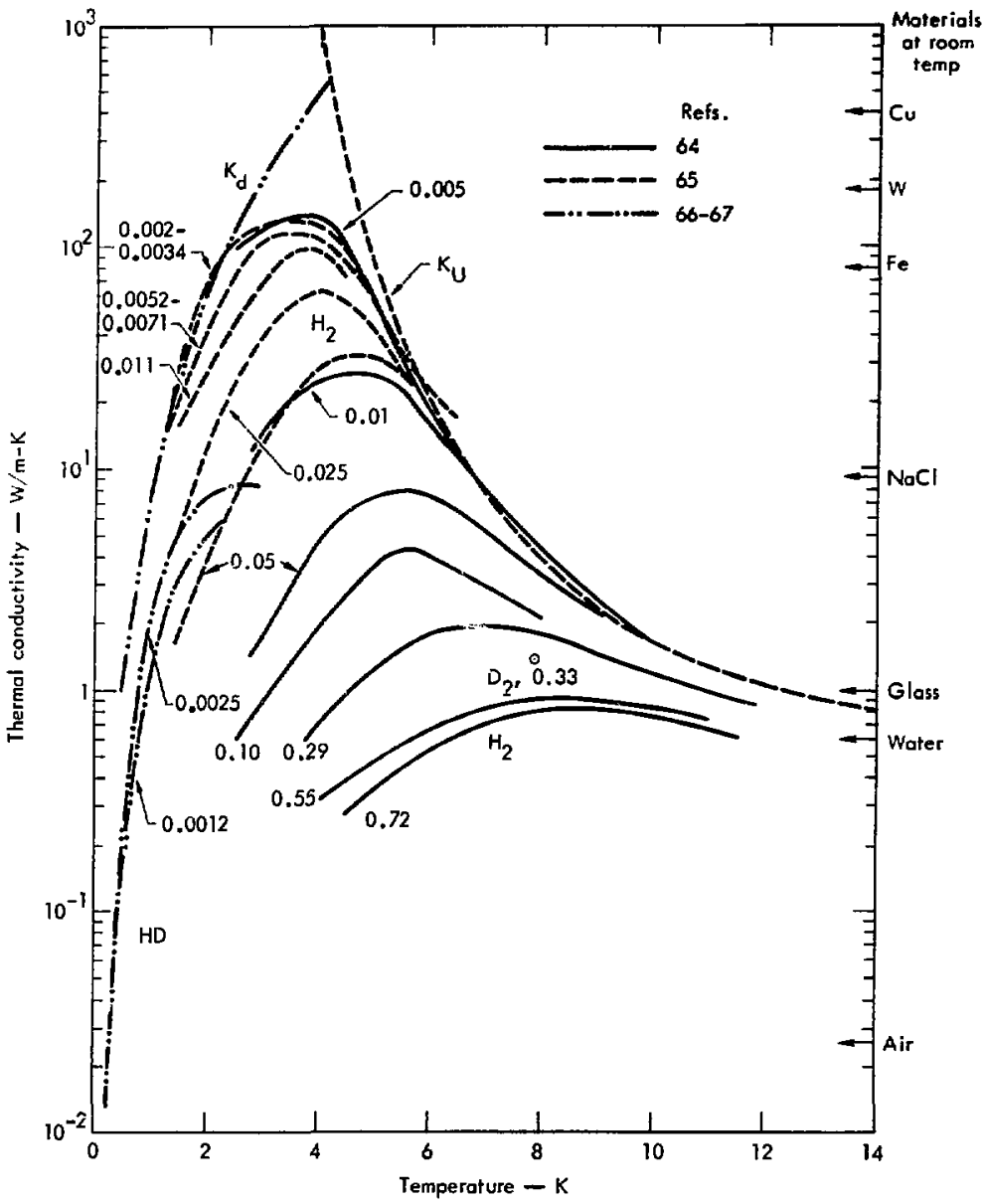

Fig. 10. Measured thermal conductivity of the solid hydrogens. 
for solid $\mathrm{H}_{2}$, but two runs have been made with solid HD containing $\mathrm{J}=1$ $\mathrm{H}_{2}$ - and $\mathrm{D}_{2}$-doped impuritles.

The right hand side of Fig. 10 also shows the themal conductivities of various common materials. ${ }^{5, *}$ The highest therwal conductivity for solid $\mathrm{H}_{2}$, with "zero" $J=1$ at $3.5 \mathrm{~K}$, compares to a room-cemperature metal with fair conductivity; e.g., tungsten. As the temperature rises to the triple point or as rotational energy is added, solld $\mathrm{H}_{2}$ takes on the thermal conductivity expected of a dielectric.

We shall now briefly mention the fragmentary data on thermal conductivity. Figure 10 shows a single $D_{2}$ point with $0.33 \mathrm{~J}=1$. This trough minimum agrees with the $\mathrm{H}_{2}$ data, Other data not shown in Fig. 10 Include "zero" $\mathrm{J}=1$ $\mathrm{H}_{2}$ at 15.1 to $17.1 \mathrm{~K}$ under pressures of 8.9 to $20.4 \mathrm{MPa}$ (88 to 201 atm). 68 The values of 0.8 to $1.0 \mathrm{~W} / \mathrm{m}-\mathrm{K}$ fit right onto the $1 \mathrm{~W} / \mathrm{m}-\mathrm{K}$ line that the hightemperature data of $\mathrm{Fig}$. 10 converge to.

Two other sources of $\mathrm{D}_{2}$ daca agree with each other but are a factor of three away from the data so far complled. The $D_{2}$ measurements for 0.02 and $0.33 \mathrm{~J}=1$ from 16.3 to $17.7 \mathrm{~K}$ yleld thermal conductivities of 2.6 to 3.2 $\mathrm{W} / \mathrm{m}-\mathrm{K} .70$ Finally, a single point of $2.6 \mathrm{w} / \mathrm{m}-\mathrm{K}$ exists for $\mathrm{D}_{2}$ at $16.75 \mathrm{~K}$ and $39 \mathrm{MPa}$ (393 atm). 71

We need other data for our analysis: $C_{I}$ from Eq. (4), the Debye temperature, $\theta_{D}$ from Eq. (6), the speed of sound, $u$, and the solid density, $\rho_{S}$. We shall use the value $2000 \mathrm{~m} / \mathrm{s}$ as an average longitudinal sound speed, $u$, for the solid hydrogens. (Sound velocity varies slightly with temperature and decreases slightly from $\mathrm{H}_{2}$ to $\mathrm{D}_{2}$. It is also a function of the crystal orlentation.) 76 For the solid densities, $\rho_{S}$, we shall ignore the slight decrease with temperature and use the triple point values. These are $\mathrm{H}_{2}=43000$ mole $/ \mathrm{m}^{3}, \mathrm{HD}=45800 \mathrm{~mole} / \mathrm{m}^{3}, \mathrm{D}_{2}=48800 \mathrm{~mole} / \mathrm{m}^{3}, \mathrm{DT}=51000 \mathrm{~mole} / \mathrm{m}^{3}$ (est imated), and $\mathrm{T}_{2}=53000 \mathrm{~mole} / \mathrm{m}^{3}$ (estimated). 7

\footnotetext{
*The two sources of $\mathrm{H}_{2}$ data differ by a factor of 4 to $5 .^{64,65}$ The differences may be caused by uncertainties in the $J=1$ concentration, $c$. This problem plagues all experiments, espectally when $c$ is low. The value of $c$ is sometimes inferred from the means of production 64 or from NMR relaxation $t$ imes, which often require supporting theory.65
} 


\section{Analysis of Thermal Conductivity}

Let us first fit equations to the $H_{2}$ "zeru" J = 1 curves* of FIg. 10 . The crystallite curve for $\mathrm{H}_{2}$ is

$$
K_{d}(c=0) \simeq 8 T^{3} \text {, }
$$

and the Umklapp curve is

$$
\mathrm{K}_{\mathrm{U}} \simeq 9 \times 10^{-6} \mathrm{~T}^{3} \exp \left\{\frac{122-1.6 \mathrm{~T}}{2 \mathrm{~T}}\right\} \text {. }
$$

Combining Eqs. (29) and (32), we obtain a low-temperature mean free path in $\mathrm{H}_{2}$ of $1.7 \times 10^{-4} \mathrm{~m}$. Combining Eqs. (30) and (33), we obtain high-temperature mean Eree paths in $\mathrm{H}_{2}$ of $1.5 \times 10^{-7} \mathrm{~m}$ at $8 \mathrm{~K}$ and $6 \times 10^{-9}$ m at the triple point.

Now let us consider the solid $\mathrm{H}_{2}$ with rotational energy. The number of phonon-phonon collisions is a function of temperature only. Therefore, the Umklapp formula - Eq. (33) - remains the same. We must modify the crystallite formula of Eq. (32) into an empirical form for $\mathrm{H}_{2}$ :

$$
K_{d}(c) \simeq \frac{\left(1.9 \times 10^{-3}\right) T^{3}}{\left[c+\left(7 \times 10^{-4}\right)\right]^{1.15}} .
$$

We have used the data of Hîll and schneidmesser, ${ }^{64}$ which covers the larger range of $c$. Equation (34) contains the number $7 \times 10^{-4}$ in the denominator to relate it to Eq. (32). This number is effectively th.: "zero" value of c in actual experimental runs. Combining Eqs. (29) and (34), we obtain the low-temperature phonon free path; 1.e., the crystallite size, as a function of c. The crystallite size is

$$
d 2 \frac{3.9 \times 10^{-8}}{\left[c+\left(7 \times 10^{-4}\right)\right]^{1.15}} \text {. }
$$

This decreases from $1.7 \times 10^{-4}$ m for "zero" $c$ to $5 \times 10^{-8} \mathrm{~m}$ for normai $(0.75 c) \mathrm{H}_{2}$.

Equations (32) to (35) carry the basic theoretical framework $f$ or the solid hydrogen thermal conductivicy. They indicate that solid hydragen consists of crystallites, whose size decreases as the fraction of $J=1$ component increases. Wall scattering of phonons of $f$ crystallites is the dominant low-temperature mechanism. For high values of $c$, the crystallites

*Actually, c is 0.002 to 0.005 . 
are almost as small as the high-temperature Umklapp mean free path. Hence, the conductivity is almost constant, but with a small peak shifted to higher temperatures. At high temperatures, wth low $c$, the Umklapp mechanism is Jominant.

The early papers ${ }^{64-66}$ accepted this theoretical view but with a Iingering reservation. Solld hydrogen easily forms beautiful, optically clear cryst 31 s with no visible grain boundarles. The first researchers, who grew $10^{-2}$ m-size sample crystals, could not entirely convince thenselves of the existence of the crystallites.

In recent times, therefore, the ambigutty of the low-temperature conductivity has given rise to a host of proposed quadrupolar mechanisms. Pussibly, phonons are scatcered by the quadrupolar-induced sublevels; $1 . e .$, the lattice vibrational energy is used to exclte a transition to an excited $m_{J}$ state. These mechanisms have led to calculared conductivity functionalities of $c^{-2} T^{-2} ;{ }^{72} c^{-1} T^{7},(c T)^{-1}, c^{-2} T^{2} ; c^{-2} T ; 67$ and $c^{-1} T .73$ There is no evidence for any of these mechanisms. The actual data, as seen by Eq. (34), are closest to the $c^{-1} T^{3}$ dependence expected from a simple crystallite theory. Possibly, a comblnation of mechanisms yields the observed results. In any case, the crystallite approach is conceptually the easiest, although the crystallite boundaries have never been experimentally observed.

Quite possibly, crystallite and phonon-sublevel rechanisms are, in fact, the same. The reduction of the phonon mean free path by $J=1$ molecules is equivalent to forming erystallites with 1nvisible boundaries. However, the crystallite mechantsm carries an easily understood $\mathrm{T}^{3}$ dependence. Such a defendence has not been explicitly demonstrated for phonon-sublevel scattering.

Equations (32) to (34) are fair descriptions of the $\mathrm{H}_{2}$ data, but extrapolation to the other hydrogens will be risky. First, these three equations tend to predict too high a conductivity for the $\mathrm{H}_{2}$ peak conductivity. Changing their parameters worsens the fit considerably at other tenperatures. Secol:d, the HD conductivity peak is an order of magnitude lower than $\mathrm{H}_{2}$ data of comparable $J=1$ content. Quite posslbly, crystallite size is a function of the history of manufacture of each given sample. 


\section{Estimated Effects of Radiation Damage}

No heat capacity or thermal conductivity measurements have been made on irradiated solid hydrogen. We shall, therefore, consider some possible analogies. In fact, it is surprising how many systems show effects simflar to those of the $J=1$ hydrogen. For the heat capacity, this is a Schottky anomaly, which peaks and dies out below $10 \mathrm{~K}$. A perfect example is seen for paramagnetic $\mathrm{O}_{2}$ impurities in solid $\mathrm{CO}$ and $\mathrm{N}_{2}$. The heat capacity anomaly peaks at $1.8 \mathrm{~K}$ for a mole fraction of 0.002 to $0.0050_{2}{ }^{77}$ The integrated energy is about $18 \mathrm{~J} / \mathrm{mole}$. The same two-level model used in Eqs. (19) to (21) is also employed in these oxygen experiments.

However, radiation can also produce defects with paramagnetic free electrons. Such free electrons have been measured by electron spin resonance (ESR) for solid hydrogen irradiaced with $\mathrm{Co}^{60} \mathrm{\gamma}$-rays, 40-MeV electrons, and tritium beta particles. ${ }^{78-82}$ Table 7 summarizes these experiments.

The species that gives rise to the ESR signal is thought to be atomfc hydroger, which saturates with radiation at about $2 \times 10^{18}$ spins/:uole. This is only $2 \times 10^{-6}$ atomic fraction - a very small amount to give such a large signal. It is a thousand times lower than the $\mathrm{O}_{2}$ amounts used in the previously described doping experiment. The total enthalpy is, therefore, about $0.018 \mathrm{~J} /$ mole. The attendant hat capcity must be zero for a:.l practical purposes.

The $\mathrm{He}^{3}$ produced by tritium decay will build up at a rate or 1 ppm per $5 \mathrm{~min}$. Such helium atoms may be trapped in the solid at low temperature rather than diffuse out and bubble away. However, a neutral He ${ }^{3}$ atom probably does not carry any force of strength comparable to the free electron. It probably will trap more heat as a defect than it will produce by splitting of the hydrogen sublevels.

We conclude, therefore, that there will probably be no large added heat capacity in solid hydrogen due to radiation. If anything, heating may anneal out defects with a production of stored energy from the sample. However, the results of damage studies in solid hydrogen could yield quite unexpected results.

Considerable evidence shows how defects affect thermal conductivity. The effect to look for will be a decreased conductivity, proportional to the concentration of the pertinent impurity, on the low temperature side of the 
Table 7. Electron spin resonance measurements on irradiated solid hydrogen at $4.2 \mathrm{~K}$.

\begin{tabular}{|c|c|c|c|c|c|c|}
\hline Isotope & $\begin{array}{c}\text { Type of } \\
\text { irradiation }\end{array}$ & $\begin{array}{c}\text { Irradiation } \\
\text { rate } \\
\text { (J/s-mole) }\end{array}$ & $\begin{array}{c}\text { ESR signal } \\
\text { saturation } \\
\text { count } \\
\text { (spins/mole) }\end{array}$ & $\begin{array}{c}\text { Energy of } \\
\text { signal } \\
\text { saturatiun } \\
\text { signal } \\
\text { (J/mole) }\end{array}$ & $\begin{array}{l}\text { Time to } \\
\text { reach } \\
\text { saturacion }\end{array}$ & Ref. no. \\
\hline $\mathrm{H}_{2}$ & $1 \mathrm{MeV} \mathrm{Y}$ & 0.033 & $3.6 \times 10^{18}$ & 1200 & $10 \mathrm{~h}$ & 78 \\
\hline $\mathrm{D}_{2}$ & $1 \mathrm{MeV} \gamma$ & 0.033 & $>4.2 \times 10^{18}$ & 1200 & $>10 \mathrm{~h}$ & 78 \\
\hline $\mathrm{H}_{2}$ & $\begin{array}{c}40 \mathrm{NeV} \\
\text { electrons }\end{array}$ & $0.15-1.5$ & $1.8 \times 10^{18}$ & 140 & $1.5-15 \mathrm{~min}$ & 79 \\
\hline $\mathbf{T}_{2}$ & $\begin{array}{c}\text { Self- } \\
\text { irradiation }\end{array}$ & 1.9 & - & $.3 .5 \times 10^{4}$ & $>4.8 \mathrm{~h}$ & 80 \\
\hline $\mathrm{H}_{2}$ & $1 \mathrm{MeV} \gamma$ & 0.033 & $6 \times 10^{17}$ & $<65$ & $30 \mathrm{~min}$ & 81 \\
\hline $\mathrm{D}_{2}$ & $1 \mathrm{MeV}^{\mathrm{Y}}$ & 0.033 & $=5 \times 10^{19}$ & $23.7 \times 10^{3}$ & $30 \mathrm{~h}$ & 81 \\
\hline $\mathrm{D}_{2}$ & $\begin{array}{l}1 \text { atom } \% \\
\mathrm{~T}_{2}\end{array}$ & 0.013 & $3 \times 10^{17}$ & $4 \times 10^{3}$ & $3.5 \mathrm{~d}$ & 82 \\
\hline
\end{tabular}


minimum. At temperatures above the minimum, all conductivity curves cend to the same value.

Extensive examples may be found in the alkali halides and metal oxides. When pure and annealed, such materlals show thermal conductivity peaks from 5 to $30 \mathrm{~K}$, wit' rystal size controlling the low-temperature portion and Umklapp processes operating at high temperatures. Decreased thermal conductivity appears in alkali halides doped with impurities at birth (e.g., $\mathrm{Li}^{+},{ }^{83} \mathrm{NI}^{+}, 84 \mathrm{CN}^{-}, 83$ or $\mathrm{OH}^{-}, 83,85$ ), Impurtities from Irradiation (e.g., U-centers ${ }^{86}$ or colloidal sflver ${ }^{87}$ ), or even dislocations caused by mechantcal stress. 88 Identical effects occur in alumina, doped wich transition elements, irradiated, or both. $89-91$

The low-temperature conductivity again shows a temperature dependence of about $\mathrm{T}^{3}$, despite a posstble variety of mechanisms. Phonon scattering from magnetic sublevels is a proninent theory because so many papers have been done on crystals doped with paramagnetic lons. However, no one has obtained satisfactory theoretical conclusions for the low-temperature conductivity.

The thermal concuctivity peak is lowered one order of magnitude with the inclusion of $2 \times 10^{-5}$ to 0.002 mole fraction of impurity, depending on the type. The peak is simultaneously moved to a temperature higher by a factor of 5 to 10 .

Especially interesting results occur for lithium fluoride (LiF) crystals irradiated with neutrons (probably just above roon temperature) to $10^{18}$ nvt (integrated neutron dose). An unirradiated, annealed crystal has a maximum thermal. conductivity at $17 \mathrm{~K}$; at $10^{18} \mathrm{nvt}$, the maximum 1 s 1 to $1 / 2$ decades lower and shifts upward to $110 \mathrm{~K}$. The conductivity appears to be saturating between $10^{17}$ and $10^{18}$ nvt. All conductivity curves intersact at $150 \mathrm{~K}$, indicating that radiation effects do not matter at higher temperatures. 92 It should be mentioned that $10^{18}$ nvt is a large enough dose to cause chemical breakdown of the LiF; $2 \%$ decomposition has been seen by NMR. ${ }^{3}$ This extent of damage caused by neutrons is illustrated by a $20 \%$ volume growth in samples irradiated at $350 \mathrm{~K}$. 94

We will expect a radiation-induced decrease in the thermal conductivity of solid hydrogen. The effect of free electron species, possible foint defects, and trapped $\mathrm{He}^{3}$ atoms w11l be to reduce the effective grain size of the hydrogen crystal, as far as phonon conduction is concerned, by physically breaking up the lattice. The ions and point defects in sulid D-T nay saturate In Ppm quantities, but the $\mathrm{He}^{3}$ will grow to much larger concentrations. 
Freshly made solid D-T will probably have the thermal conductivity of unirradiated hydrogen. Over the space of a few days, accumulating damage may roduce the phonon mean free path to the constant va.iue of about $10^{-8} \mathrm{~m}$ or less. Then we have a possible situation with a small mean free pith but also a sma 1 heat capacity. This is the situation that will produce the lowest possible thermal conductivity. Defects scatier the phonons; yet the energy bound in the defects is probably not available to the phonons.

We use the form of Eq. (29) with the crystallite size limited to a sma1l, constant value at all temperatures by the radiaticn damage. Let us use the d value of $10^{-8} \mathrm{~m}$, close to the very lowest value obtained from the Umklapp calculation at the $\mathrm{H}_{2}$ triple point. Then, we have the approximate estimate of

$$
\mathrm{k}_{\mathrm{rad}} \sim 1.3 \times 10^{-8} \mathrm{~T}^{3} \rho_{\mathrm{S}}
$$

For $\mathrm{H}_{2}$, we obtain an equation much like Eq. (32) but yielding thermal conductivities 10000 times lower. At $3.5 \mathrm{~K}$, the conductivity has finally rijen to that of room-temperature air - a good insulator. The conductivity continues to rise with temperature until it intersects the unirradiated Unklapp line near the triple point.

\section{Estimates for D-T}

It is easy to estimate values for $D-T$, if the 1 ikely assumption is made that the $\mathrm{D}_{2}$ and $\mathrm{T}_{2}$ are in equilibrium rotational states. Below $25 \mathrm{~K}$, the rotational effects of equilibrium $\mathrm{J}=1$ molecules are not great. We need not sum properties for each component $-\mathrm{D}_{2}, \mathrm{DT}, \mathrm{T}_{2}-$ but we may condense all properties as though only DT were present. Figure 11 shows the crystal lattice heat capacity estimate for D-T, which is basically just an extension of the $D_{2}$ data of Table 1 .

Eigure 11 also shows the estimated thermal colwuctivity for solid D-T. The available data are simply not good enough to make straightforward estimates. We, therefore, present "high" and "1ow" estimates. The former curves are based on the $\mathrm{H}_{2}$ data of Fig. 10; the latter curves are a decade lower and are representative of the $\mathrm{HD}$ data.

The extreme sensitıvity of the thermal conductivily adds further uncertainty. "Just frozen" D-T drops two decades in sonductivi4y upon warming from $4 \mathrm{~K}$ to the triple point. Low-temperature D-T may drop as much as four 


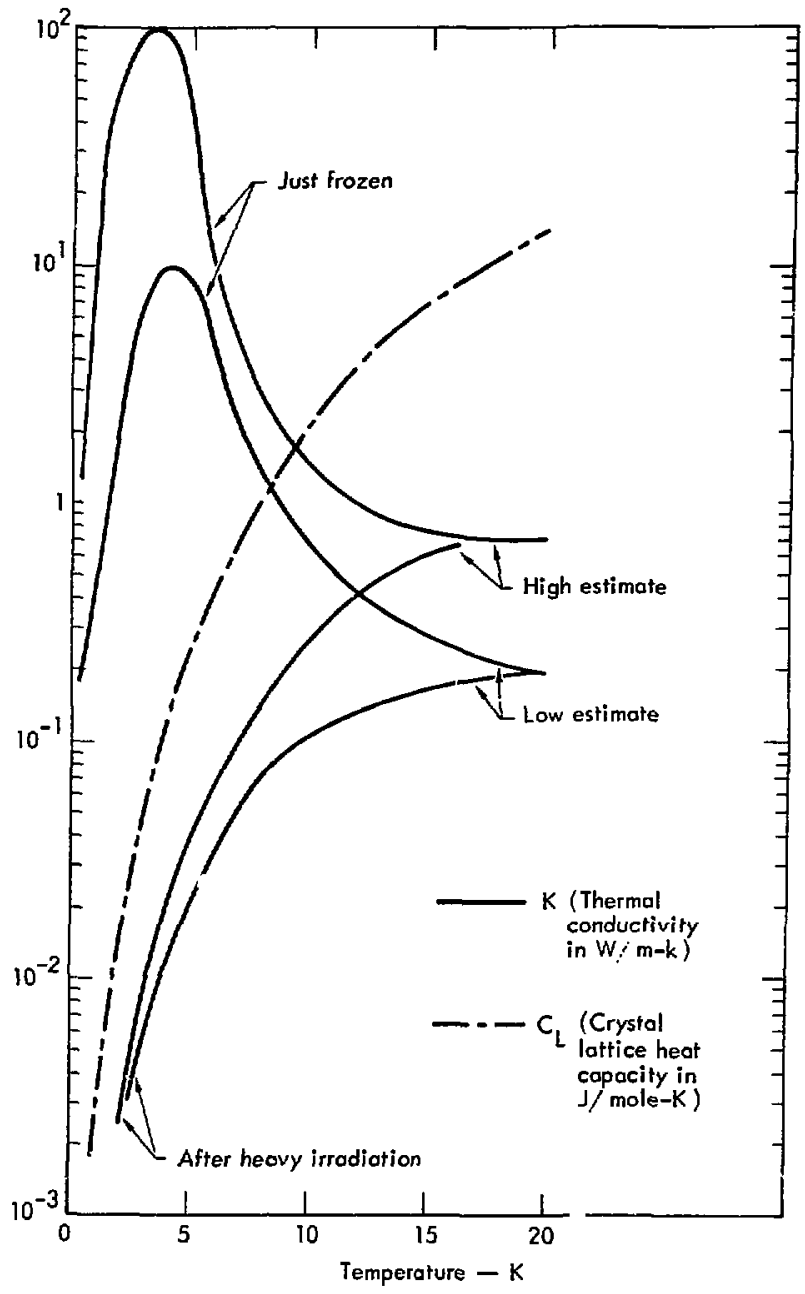

F1g. 11. Estimated crystal lattice heat capacity and thermal conductivity of solid D-T (assumed equilibrium). 
to five decades in conductivity as radiation damage destroys the crystal lattice. The rate of this important transforination is unknuwn.

We now move on one more step to estimate the thermal diffusivity of solid D-T. Thermal diffusivity, $D_{S}$, is

$$
\mathbf{D}_{\mathbf{S}}=\frac{\mathbf{k}_{\mathbf{S}}}{\mathbf{C}_{\mathrm{L}} \rho_{\mathrm{S}}} \text {, }
$$

where, again, only the crystal ?attice heat capacity is used as the energy rerm. 95 Figure 12 shows the estimates, which range over a remarkable flve-and-a-half decades as functions of temperature and radiation.

\section{Acknowledgments}

We wish to thank Carol Briggs for her asslstance in locating heat capacity data and in plotting Fig. 2 and Leslle Schwartz for Einding the ESR data. We also would like to thank $J$. Pyper for his calculations of hydrogen exchange equilibria. For support in DT cryogenics, we would like to thank 3. Emmett and C. D. Hendricks of the Lawrence Livermore Laboratory Laser Program. We would also 1ike to thank the Division of Physical Research of the Energy Research \& Development Administration. 


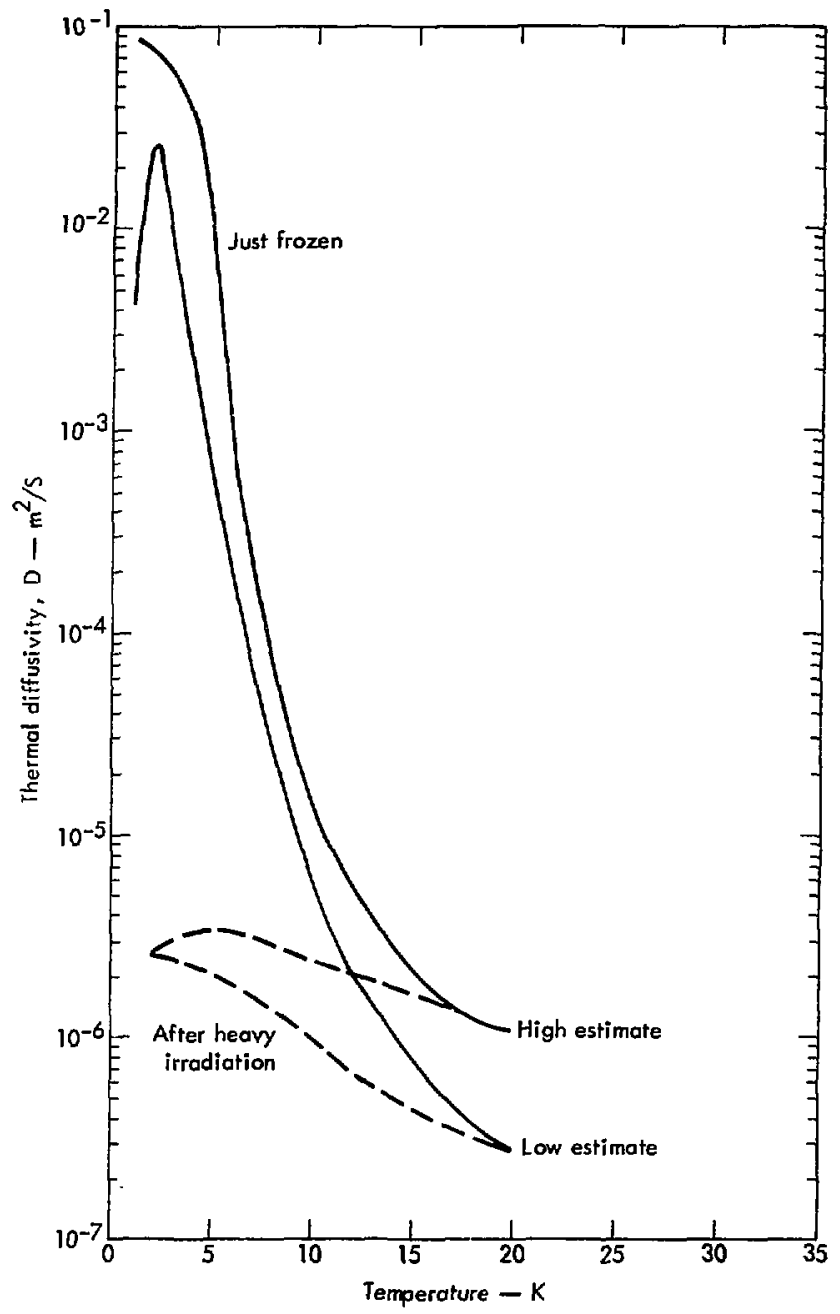

Fig. 12. Estimated thermal diffusivity of solid D-T (assumed equilibrium). 


\section{References}

1. J. Emmett, J. Nuckolls, and L. Wood, Sci. Amer. 230 (6), 24 (1974).

2. H. H. Fleischmann, Phys. Today 28, (5), 34 (1975).

3. R. F. Post, Phys. Today 26, (4), 31 (1973).

4. R. T. Tsugawa, D. Fearon, P. C. Souers, R. G. Hickman, and P. E. Roberts, "A Secondary Containment System for a High-Tritium Research Cryostat," Proc. Intern. Conf. Radiation Effects and Trittum Technology for Fusion Reactors, presented Gat linburg, TN, Oct. 1-3, 1975.

5. P. C. Souers, R. G. Hickoman, and R. T. Tsugawa, "Estimated $\mathrm{D}_{2}-\mathrm{DT}-\mathrm{T}_{2}$ Phase Diagram in the Three-Phase Region," Proc. Intern. Conf. Radiation Effects and Tritium Technology for Fusion Reactors, presented Gatlinburg, TN, 0ct. 1-3, 1975.

6. C. K. Brlggs, R. G. Hickman, R. T. Tsugawa, and P. C. Souers, Estimated Viscostty, Surface Tension, and Density of Liquid DT from the Triple Polnt to 25K, Lawrence Ifvermore Laboratory, Rept. UCRL-51827 (1975).

7. C. K. Briggs, R. T. Tsugawa, C. D. Hendricks, and P. C. Souers, Estimated Refractive Index and Solid Density of DT, with Application to HollowMicrosphere Laser Targets, Lawrence LIvermore Laboratory, Rept. UCRL-51921 (1975).

8. P. C. Souers, R. G. Hickman, H. Z. Wade, and R. T. Tsugawa, Estimated Infrared Spectra of Cryogenic $\mathrm{D}_{2}-\mathrm{DT}-\mathrm{T}_{2}$, Lawrence Livermore Laboratory, Reṕt. UCRL-51674 (1975).

9. C. K. Briggs, R. G. Hickman, R. T. Tsugawa, and P. C. Souers, "Estimates of Some Cryogenic DT Properties," Proc. Intern. Conf. Radiation Effects and Tritium Technology for Fuston Reactors, Gatlinburg, TN, Oct. 1-3, 1975.

10. H. M. Roder, G. E. Childs, R. D. McCarty, and P. E. Angerhofer, Survey of the Properties of the Hydrogen Isotopes Below Their Critical Temperatures, National Bureau of Standards, Washington, D.C., Rept. NBS-641 (1973), pp. 87-96.

11. J. W. Pyper and P. C. Souers, The Chemical Equilibria Relating the Isotopic Hydrogens, A Review, Lawrence Livermore Laboratory, UCRL to be published.

12. K. Mendelssohn, M. Ruhemann, and F. Simon, Z. Phys. Chem- B15, 121 (1931).

13. H. W. Woolley, R. B. Scott, and F. G. Brickwedde, J. Res. Nat. Bur. Stand. 41 379 (1948).

14. H. L. Johnston, J. T. Clarke, E. B. Rifkin, and E. C. Kerr, J. Aner. Chen. Soc. $\underline{72}, 3933$ (1950).

15. R. W. H111 and B. H. A. Ricketson, Phil. Mag. 45,277 (1954). 
16. R. W. Hill and O. V. Lounasmaa, Phil. Mag. 4, 785 (1959).

17. G. Ahlers, Some Properties of Solid Hydrogen at Small Molar Volumes, Lawrence Radiation Laboratory, Rept. UCRL-10757 (1963).

18. G. Ahlers, J. Chen. Phys. 41, 86 (1964).

19. D. White and J. R. Gaines, J. Chem. Phys. 42, 4152 (1565).

20. D. White and J. R. Gaines, Low Temperature Physics LT9, Part B, J. G. Daunt, Ed. (Plenum Press, New York, 1965), pp. 1104-1109.

21. R. J. Roberts and J. G. Daunt, Phys. Lett. 33A, 353 (1970).

22. R. J. Roberts and J. G. Daunt, J. Low Temp. Phys. 6, 97 (1972).

23. V. G. Manzhelii, V. A. Popov, G. P. Chausov, and L. I. Vladimirova, J. Low Temp. Phys. 14, 397 (1974).

24. G. Grenier and D. White, J. Chem. Phys. 40, 3451 (1964).

25. J. H. Constable, A. Q. MeGee, and J. R. Gaines, Phys. Rev. 11B, 3045 (1975).

26. K. Clusius and E. Bartholune, Z. Phys. Chem. B30, 237 (1935).

27. E. C. Kerr, E. B. Rifkin, H. I. Joiznston, and J. T. Clarke, J. Amer. Chem. Soc. 73,282 (1951).

28. O. D. Gonzalez, D. White, and H. L. Johnston, J. Phys. Chen. 61, 773 (1957).

29. G. Grenier and D. White, J. Chem. Phys. 40, 3015 (1964).

30. R. J. Roberts and J. G. Daunt, J. Low Temp. Phys. 16, 405 (1974).

31. NBS-641, pp. 30-39.

32. C. Kittel, Introduction to Solld State Physles (John Wiley, New York, 1971) 4th ed., Pp. 215-217.

33. American Institute of Phystcs Handbook, D. E. Gray, Ed. (McGraw-Hi11, New York, 1972) 3rd ed., pp. 4-113.

34. E. W. Albers, P. Harteck, and R. R. Reeves, Z. Naturforsch. 18A, 197 (1963).

35. E. W. Albers, P. Harteck, and R. R. Reeves, J. Aner. Chem. Soc. 86, 204 (1964).

36. R. Frauenfelder, F. Helnrich, and J. B. Olin, Helv. Phys. Act. 38, 279 (1965).

37. G. Herzberg, Molecular Spectra and Molecular Structure, I: Spectra of Diatomic Molecules (Van Nostrand Reinhold Co., New York, 1950), 2nd ed., pp. $98,530-533$. 
38. J. F, Lee, F. W. Sears, and D. L. Turcotte, Statistical Thermodynamics (Addison-Wesley, Reading, Massachusetts, 1963), Pp. 208-214.

39. G. N. Lewis and M. Randa11, Thermodynamics, rev. by K. S. P1tzer and L. Brewer (McGraw-H111, New York, 1961), 2nd ed., pp. 421-426, 595-601.

40. D. M. Dennison, Proc. Royal Soc. A115, 483-480 (1927).

41. F. Simon, K. Mendelssohn, and M. Ruhemann, Naturw1ss. 18, 34 (1930).

42. L. Pauling, Phys. Rey. 36, 420 (1930).

43. J. Hatton and B. V. Rollin, Proc. Royal Soc. A199, 222 (1949).

44. F. Reif and E. M. Purce11, Phys. Rev. 91, 631 (1953).

45. K. P. Belov, Magnetic Transitions, trans. from Russian by W. H. Furry (Consultants Bureau, New York, 1961), Pp. 1-4, 132-134.

46. A. B. Harris, J. Appl. Phys, 42, 1574, (1971).

47. W. H. Orttung, J. Chem. Phys. 36, 652 (1962).

48. K1tte1, p. 523 .

49. T. Nakamaura, Progr. Theor. Phys. 14, 135 (1955).

50. H. Miyagi, Pragr. Thearet. Phys. 40, 1448 (1968).

51. M. Clouter and H. P. Gush, Phys. Rev. Lett. 15, 200 (1965).

52. R. L. M1lls anj A. F. Schuch, Phys, Rev. Lett. 15, 722 (1965),

53. R. L. Mi11s, A. F. Schuch, and D. A. Depatle, Phys. Rev. Lett. 17, 1131 (1966).

54. J. Jarv1s, D, Ramm, and H. Meyer, Phys. Rev, Letc. 18, 119 (1967).

55. A. F. Schuch, R. I. Mills, and D. A. Depatie, Phys, Rev. 165, 1032 (1968).

56. F. W. Smith and R. M. Housley, Phys. Rev. 117, 732 (1960).

5\%. R. W. Hill, B. W. A. Ricketson, and F. Simon, in Conf. de Physique des Basseg Temperatures, Paris, 1955 (Institut International du Froid, Paris, 1955), p. 317, cited in Ref. 55.

58. A. B. Harris, Phys. Rev. 1B, 1881 (1970).

59. W. N. Hardy and J, R. Gaines, Phys. Rev. Lett. 19, 1417 (1967).

60. J. H. Constable and J. R. Galnes, Solid State Commun. 9, 155 (1971).

61. P. Pedron1, M. Chan, R. Schweizer, and H. Meyer, J. Low Temp. Phys, 19, 537 (1975). 
62. Kitte1, Pp. 224-233.

63. R. Berman, "The Thermal Conductivity of Dielectric Solids at Low Temperatures," Advan. in Phys. 2, 103 (1953).

64. R. W. H11l and B. Schneidmesser, Z. Phys. Chem., Neue Folge 16, 257 (1958).

65. R. G. Bohn and C. F. Mate, Phys. Rev. 2B, 2121 (1970).

66. J. H. Constable and J. R. Gaines, in Proc. Intern. Conf. Low Temp. Phys., 13ch, Boulder, Colo., 1972 (Plenum, New York, 1974), vol, 2, PP, 223-226.

67. J. H. Constable and J. R. Gaines, Phys. Rev. 8, 3966 (1973).

68. B. F. Dwyer, G. A. Cook, and 0. E. Bexwaldt, J. Chem. Eng. Data 11, 351 (1966).

69. R. W. Hill and B. Schneidmesser, Bull. Inst. Int. Froid, Annexe 2, 115 (1956), cited In Ref. 67.

70. D. E. Daney, Cryogenics 11, 290 (1971).

71. L. D. Ikenberry and S. A. Rice, J. Chem. Phys. 39, 1561 (1963).

72. C. Ebner and C. C. Sung, Phys. Rev. 2B, 2115 (1970).

73. V. B. Kokshenev, J. Low Temp. Phys. 20, 373 (1975).

74. NBS-641, PP. 39-41.

75. Handbook of Chemistry and Physics, R. C. Weast, ed. (The Chemical Rubber Co., Cleveland, 1972-1973), 53rd ed., Pp. E-4 to E-10.

76. R. Wanner and H. Meyer, Phys. Lett. 41A, 189 (1972).

77. J. C. Burford and G. M. Grahan, J. Chen. Phys. 49, 763 (1968).

78. L. A. Wa11, D. W. Brown, and R. E. Flor1n, J. Phys. Chem. 63, 1762 (1959).

79. L. H. Piette, R. C. Rempe1, H. E. Weaver, and J. M. Flournoy, I. Chem.

Phys. 30, 1623 (1959).

80. J. Lambe, Phys. Rev. 120, 1208 (1960).

81. D. W. Brown, R. E. Florin, and L. A. Wal1, J. Phys. Chen. 66, 2602 (1962).

82. M. Sharnoff and R. V. Pound, Phys. Rev. 132, 1003 (1963).

83. F. P. Peressin1, J. P. Harrison, and R. O. Pohl, Phys. Rev. 182, 939 (1969).

84. J. Donecker, Phys, Status Solid1 S1B, 821 (1972). 
85. R. L. Rosenbaum, C. K. Chau, and M. V. KleIn, Phys. Rev. 186, 852 (1969).

86. L. G. Radosevich and C. T. Walker, Phys. Rev. 171, 1004 (1968).

87. W. Bausch, F. Guckenbiehl, and W. Waldel1ch, Phys. Lett. 28A, 38 (1968).

88. T. Suzuk1 and H. Suzuk1, J. Phys. Soc. Japan 32, 164 (1972).

89. A. M. deGoer and B. Dreyfus, Phys. Status Sol1d 22,77 (1967).

90. A. M. deGoer, J. Physique 30,389 (1969).

91. A. M. deGoer and N. Devismes, J. Phys. Chem. Solids 33, 1785 (1972).

92. U. Himmler, H. Peis1, and W. Waidelich, Z. Angew Phys. 19, 468 (1965).

93. C. Knutson, B. Hooper, and P. Bray, J. Phys. Chem. Sol1ds 27, 147 (1966).

94. J. Spaepen, Phys. Rev. Lett. 1, 281 (1958).

95. I. S. Sokolnikoff and R. M. Redheffer, Mathematics of Physics and Engineering (McGraw-Hill, New York, 1958), pp. 455-463. 


\section{Appendix: Calculation of Heat Capacities and Enthalpies at 4.2 and $19.7 \mathrm{~K}$}

We have mentioned that $\mathrm{eD}_{2}-\mathrm{DT}-\mathrm{eT}_{2}$ does not require component-by-component sumation of thermal properties. We shall show the results of such a calculation here anyway. This will be contcasted with a calculation for $\mathrm{nD}_{2}-\mathrm{DT}-\pi \mathrm{T}_{2}$, whicin we shall assume to be metastably trapped at low temperature. In this case of high rotational energy, each compcnent must be calculated and the results summed. We recall that DT is always in the equilibrium form.

The compositions for $1: 1 \mathrm{D}-\mathrm{T}\left(\mathrm{D}_{2}-\mathrm{DT}-\mathrm{T}_{2}\right)$ are: $0.46 / 0.08 / 0.46$ at $4.2 \mathrm{~K}$ equilibrium; $0.31 / 0.38 / 0.31$ at $19.7 \mathrm{~K}$ equilibrium; and $0.25 / 0.50 / 0.25$ at normal temperature. 10

Tables 8 and 9 present estimated and calculated heat capacities and enthalpies for $D-T$.

Table 8. Estimated enthalpy and heat capacity for solid D- $\mathrm{T}$ at $4.2 \mathrm{~K}$

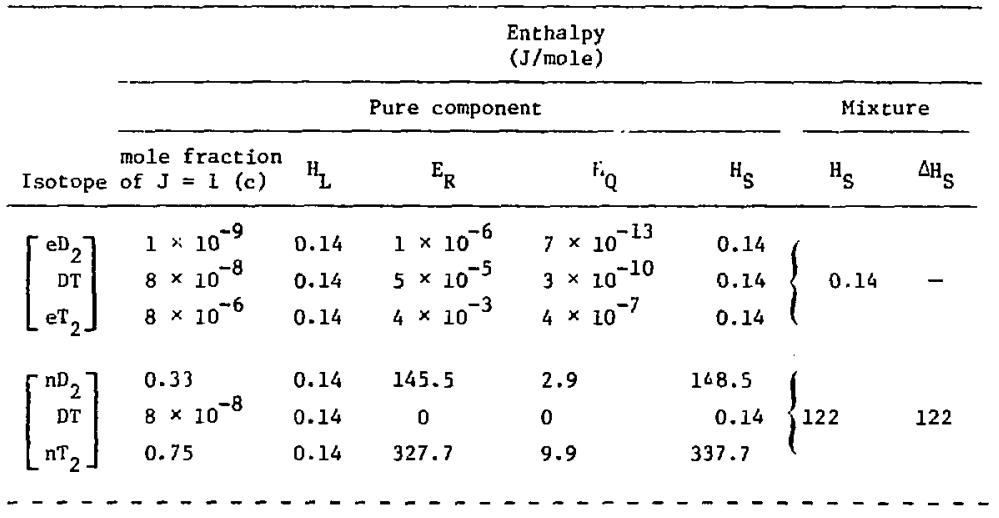


Table 8. (continued)

\begin{tabular}{|c|c|c|c|c|c|c|c|}
\hline \multirow[b]{3}{*}{ Isotope } & \multicolumn{7}{|c|}{$\begin{array}{l}\text { Heat capacity } \\
(\mathrm{J} / \mathrm{mole}-\mathrm{K})\end{array}$} \\
\hline & \multicolumn{5}{|c|}{ Pure component } & \multicolumn{2}{|c|}{ Mixture } \\
\hline & c & $c_{\mathbf{L}}$ & $\mathrm{C}_{\mathrm{R}}$ & $\mathrm{c}_{\mathrm{Q}}$ & $c_{s}$ & $c_{s}$ & $\Delta c_{\mathrm{S}}$ \\
\hline$[\mathrm{eII}$ & $1 \times 10^{-9}$ & 0.13 & $5 \times 10^{-6}$ & $1 \times 10^{-13}$ & 0.13 & & \\
\hline DT & $8 \times 10^{-8}$ & 0.13 & $2 \times 10^{-4}$ & $5 \times 10^{-11}$ & 0.13 & 0.13 & - \\
\hline & $8 \times 10^{-6}$ & 0.13 & 0.013 & $5 \times 10^{-8}$ & 0.13 & & \\
\hline$\left[\mathrm{nD}_{2}\right.$ & 0.33 & 0.13 & 0 & 0 & 0.13 & & \\
\hline $\mathrm{DT}$ & $8 \times 10^{-8}$ & 0.13 & 0 & 0 & 0.13 & 0.13 & 0 \\
\hline $\mathrm{nT}_{2}$ & 0.75 & 0.13 & 0 & 0 & 0.13 & & \\
\hline
\end{tabular}

Table 9. Calculated enthalpy and heat capacity for solid D-T at $19.7 \mathrm{~K}$ (estimated triple point).

\begin{tabular}{|c|c|c|c|c|c|c|c|}
\hline \multirow[b]{3}{*}{ Isotope } & \multicolumn{7}{|c|}{$\begin{array}{l}\text { Enthalpy } \\
\text { (J/mole) }\end{array}$} \\
\hline & \multicolumn{5}{|c|}{ Pure component } & \multicolumn{2}{|c|}{ Mixture } \\
\hline & $\begin{array}{l}\text { mole fraction } \\
\text { of } J=1 \text { (c) }\end{array}$ & $\mathrm{H}_{\mathrm{L}}$ & $\mathrm{E}_{\mathrm{R}}$ & $\mathrm{H}_{\mathrm{Q}}$ & $\mathrm{H}_{\mathrm{S}}$ & $\mathrm{H}_{\mathrm{S}}$ & $\Delta \mathrm{H}_{\mathrm{S}}$ \\
\hline$\left[\mathrm{eD}_{2}\right.$ & 0.017 & 73.9 & 12.6 & 0.05 & 86.6 & & \\
\hline $\mathrm{DT}$ & 0.067 & 73.9 & 41.1 & 0.40 & 115.4 & 143 & 一 \\
\hline $\mathrm{eT}_{2}$ & 0.32 & 73.9 & 154.0 & 4.1 & 232.0 & & \\
\hline$\left[\mathrm{nD}_{2}\right]$ & 0.33 & 73.9 & 145.5 & 4.4 & 223.8 & & \\
\hline $\mathbf{D T}$ & 0.067 & 73.9 & 0 & 0 & 73.9 & 197 & 54 \\
\hline$n \mathrm{~T}_{2}$ & 0.75 & 73.9 & 327.7 & 14.9 & 416.5 & & \\
\hline
\end{tabular}


Table 9. (continued)

\begin{tabular}{|c|c|c|c|c|c|c|c|}
\hline \multirow[b]{3}{*}{ I sotope } & \multicolumn{7}{|c|}{$\begin{array}{l}\text { Heat capacity } \\
(\mathrm{J} / \mathrm{mole}-\mathrm{K})\end{array}$} \\
\hline & \multicolumn{5}{|c|}{ Pure component } & \multicolumn{2}{|c|}{ Mixture } \\
\hline & c & $\mathrm{c}_{\mathrm{L}}$ & $c_{\mathrm{R}}$ & $\mathrm{C}_{\mathrm{Q}}$ & $\mathrm{C}_{\mathrm{S}}$ & $c_{S}$ & $\Delta \mathrm{C}_{\mathrm{S}}$ \\
\hline$\left\lceil\mathrm{eD}_{2}\right\rceil$ & 0.017 & 13.5 & 2.8 & $2 \times 10^{-4}$ & 16.3 & & \\
\hline $\mathrm{DT}$ & 0.067 & 13.5 & 7.3 & $2 \times 10^{-3}$ & 20.8 & 22.0 & - \\
\hline $\mathrm{LeT}_{2}$ & 0.32 & 13.5 & 15.8 & 0.018 & 29.3 & & \\
\hline$\left\lceil\mathrm{aD}_{2}\right]$ & 0.33 & 13.5 & 0 & 0 & 13.5 & & \\
\hline DT & 0.067 & 13.5 & 0 & 0 & 13.5 & 13.5 & 8.5 \\
\hline$n r_{2}$ & 0.75 & 13.5 & 0 & 0 & 13.5 & & \\
\hline
\end{tabular}

